\title{
Stefan Groh
}

\section{Amphitheater in Noricum}

Die Publikation der Grabungen 1998 bis 2001 im Amphitheater von Virunum gab den Anstoß, eine zusammenfassende Darstellung und Analyse dieses Bautyps für die Provinz Noricum vorzunehmen (Abb. 1) ${ }^{1}$. Lange Zeit war nur der Grundriss des 1917 unter der Leitung von W. Schmid freigelegten Amphitheaters von Flavia Solva bekannt, welcher auch Eingang in die regionale und überregionale Literatur fand ${ }^{2}$. Erst 1934 gelang F. Jantsch die Identifizierung des Amphitheaters von Virunum anhand von Bebauungsmerkmalen im Gelände ${ }^{3}$, ein exakter Grundriss des Baus wurde jedoch, abgesehen von Vorberichten, erst mit der Vorlage im Jahr 2004 bekannt ${ }^{4}$. Neben den

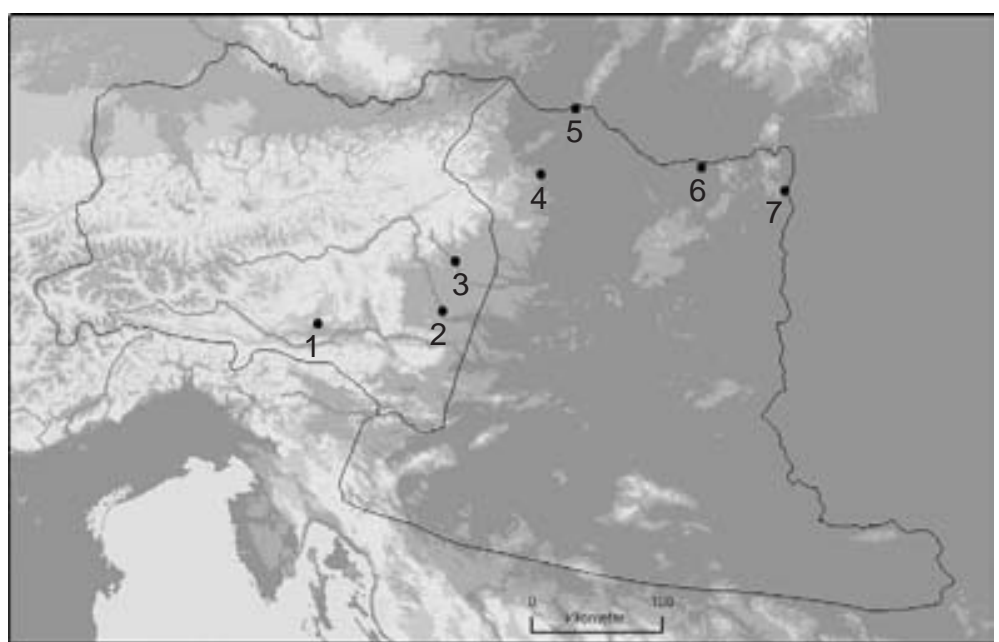

1 Verbreitungskarte der Amphitheater in Noricum und Pannonien: 1 Virunum, 2 Flavia Solva, 3 Gleisdorf, 4 Scarbantia, 5 Carnuntum, 6 Brigetio, 7 Aquincum Amphitheatern von Virunum und Flavia Solva wurde 1948-50 von W. Schmid im Vicus von Gleisdorf ein weiteres Amphitheater untersucht ${ }^{5}$.

Die Errichtung dieser drei Großbauten öffentlichen Interesses reflektiert den hohen Grad der Urbanisierung der Provinz und Prosperität der Gemeinwesen, darüber hinaus stellte sie ein wichtiges Mittel der politischen Propaganda dar. Der Bau eines Amphitheaters, die damit verbundene Ausrichtung von Spielen, Aufzügen und Tierhatzen, Weihung von Altären sowie die Finanzierung der anfallenden Renovierungsarbeiten boten ausreichend Betätigungsfelder für lokale Verbände, Verwaltungsorgane und die Nobilität. Amphitheater besitzen demzufolge neben ihrem funktionalen Aspekt - der Zerstreuung und Belustigung einer urbanen und suburbanen Bevölkerung (panem et circenses) ${ }^{6}$ - einen hohen repräsentativen Stellenwert.

Ziel dieses Beitrags ist es zu hinterfragen, ob in der Provinz Noricum von einem einheitlichen Bauprogramm für Amphitheater auszugehen ist, ferner wie sich diese Bauten hinsichtlich ihrer chronologischen, typologischen und funktionalen Einordnung zueinander und zu jenen der Nachbarprovinzen verhalten.

\section{Die archäologischen Befunde der norischen Amphitheater}

\section{Gleisdorf}

Bei Grabungen der Jahre 1948-50 wurde im römischen Vicus von Gleisdorf (Oststeiermark) ein $66 \times 46 \mathrm{~m}$ großer, von einer 1-1,2 m starken Fundamentmauer umgebener Ovalbau partiell freigelegt, den man als

\footnotetext{
${ }^{1}$ Für die Diskussion danke ich H. Sedlmayer und R. Wedenig.

2 Alföldy 1974, 94 f.; Hudeczek 1977, 456 Abb. 14; zu den Amphitheatern in Noricum: Golvin 1988, 91 Nr. 51.52 (Virunum und Flavia Solva) - das Amphitheater von Gleisdorf fand bei J.-C. Golvin keine Berücksichtigung.

3 Jernej 2004, 19.

${ }^{4}$ Jernej - Gugl 2004.

5 Alföldy 1974, 140.

${ }^{6}$ Iuv. 10, 75 ff.
} 


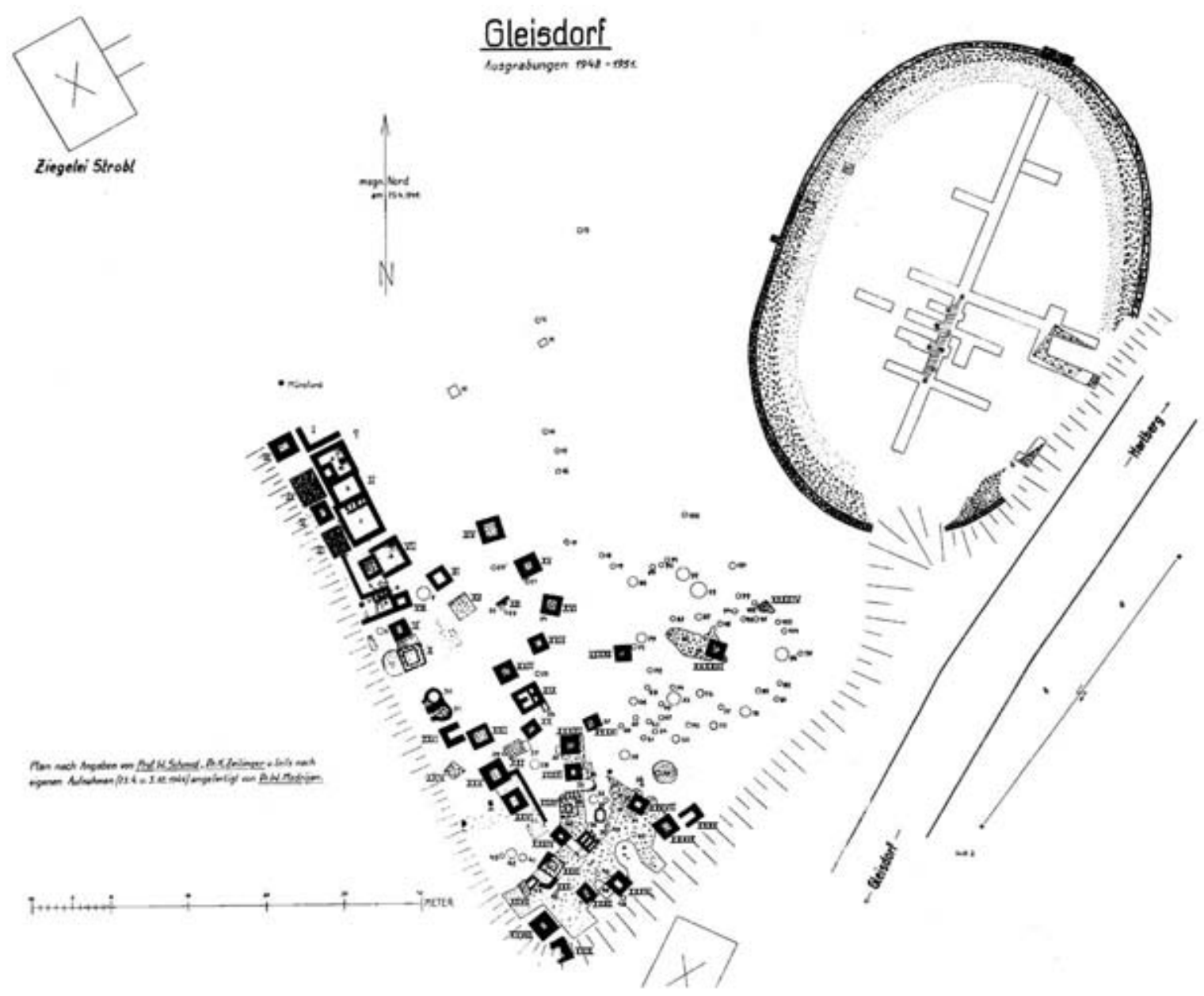

2 Nördlicher Gräberbezirk und Amphitheater des Vicus von Gleisdorf, Grabungen 1948-51

Amphitheater deutete (Abb. 2) ${ }^{7}$. Der Bau lag am nördlichen Siedlungsrand in unmittelbarer Nachbarschaft zu einem Gräberbezirk und entlang der Ausfallstraße, die das nördliche Raabtal erschloss ${ }^{8}$. Diese Lage bezeugt die Einbindung des Amphitheaters in das lokale und überregionale Straßennetz. Gräberbezirk und Ovalbau befanden sich auf der obersten Terrasse eines quartären Lehmplateaus am linken Raabufer (ca. 365 m ü[ber] A[dria]) in leichter Spornlage, die Siedlung erstreckte sich ca. $10 \mathrm{~m}$ tiefer bis in die Tallagen der Raab. Der Ovalbau nahm an der höchsten Stelle eine dominante Position über dem Siedlungsgebiet ein.

Die Mauern des Baus fertigte man sehr inhomogen in unterschiedlichen Mauertechniken, sie setzten sich aus Bereichen mit Kalk- und Muschelkalkstein im Südwesten sowie Ziegelbruch und Sandsteinen im Westen und Norden zusammen. Eine $4 \mathrm{~m}$ breite, axial im Norden gelegene Pflasterung könnte als Zugang interpretiert werden. Innerhalb der Arena säumte die Innenseite der Mauern eine 2-3,2 m breite Pflasterung, auf die eine ebenso breite Sandschicht folgte. Im Südteil der Arena wurden Steinsetzungen dokumentiert, die verkohlte Pfostenreste umschlossen. Brandschutt und -spuren waren vor allem im südlichen Abschnitt des Baus sowohl auf den Mauerkronen als auch in der Arena selbst festzustellen. In den spärlichen Grabungsberichten werden keine Spuren einer Eintiefung der Arena oder einer Aufschüttung für die Zusehertribünen der Cavea erwähnt, das Bauwerk selbst fiel dem fortschreitenden Lehmabbau zum Opfer. Die Cavea konnte jedoch ursprünglich nicht breiter als $13 \mathrm{~m}$ gewesen sein ${ }^{9}$, da sich in dieser Entfernung südwestlich des Theaters bereits die ersten Bestattungen des Gräberfeldes (Hartbergerstraße) befunden haben. Die dem Amphitheater nächst gelegenen

\footnotetext{
${ }^{7}$ W. Schmid - K. Zeilinger, Gleisdorf, FB 5, 1946-50, 125 ff. bzw. Maier 1995, 30 f.

${ }^{8}$ Maier 1995, $31 \mathrm{f}$.

${ }^{9}$ Vgl. dazu die Tribünen des Amphitheaters von Silchester in der Steinphase 1 mit 12 m Breite (Fulford 1989, 172 Abb. 73).
} 
Gräber datieren von der Mitte des 1 . bis zur Mitte des 3. Jahrhunderts n. Chr. ${ }^{10}$, was als Indiz für eine von Siedlungsbeginn an geplante Anlage des Amphitheaters gewertet werden darf.

In seinem Grundriss entspricht das Amphitheater dem von J.-C. Golvin definierten Typ des »amphithéâtre à structure pleine« (hier Typ 1), der sich durch eine einfache Konstruktion, zumeist nur partiell eingetiefte Arena und aufgeschüttete Cavea auszeichnet. Letztgenannte wurde entweder zur Gänze oder unter Berücksichtigung des Geländes nur teilweise auf einer Aufschüttung errichtet. Golvin definiert weiter zwei Untertypen, die sich hinsichtlich des Konstruktionsschemas der Cavea unterscheiden: Typ 1a mit einer durchgehenden Aufschüttung der Cavea und Typ 1b mit parallelen Mauerringen und radialen Zwischenmauern in der Substruktion der Cavea ${ }^{11}$. Der Bau in Gleisdorf dürfte eine durchgehende Aufschüttung für die Cavea besessen haben, zumindest wurden keine Mauern außerhalb der Begrenzungsmauer der Arena ergraben oder dokumentiert.

Der Gleisdorfer Bau weist mehrere Umbauphasen auf, unterschiedliches Mauerwerk in zusammenhängenden Abschnitten deutet auf Ausbesserungsarbeiten und partielle Erneuerungen von Mauerzügen. Die Gesamtfläche der Arena betrug $2250 \mathrm{~m}^{2}$, womit das Amphitheater weit über der durchschnittlichen Arenenfläche dieses Typs ( $\left.1450 \mathrm{~m}^{2}\right)$ lag $^{12}$. Das Verhältnis der Längsachse a zur Achse b ( = $\left.\frac{a}{b}\right)$ entsprach dem Koeffizienten 1,43, damit nahm der Bau im Vergleich zu den übrigen römischen Amphitheatern eine Position im Mittelbereich der Anlagen mit einer sehr rundlichen und jenen mit einer äußerst langgestreckten Arena ein ${ }^{13}$.

\section{Flavia Solva}

Das Amphitheater von Flavia Solva wurde 1917 mithilfe Kriegsgefangener aus dem Barackenlager Wagna freigelegt und als Gebäude XV bezeichnet (Abb. 3. 4) ${ }^{14}$. Der Bau lag - eingebunden in die urbane Bebauung am südwestlichen Stadtrand in der Ebene des Leibnitzer Feldes (267 m üA). Die noch heute im Gelände sichtbare Anomalie (Senke) im Bereich des Amphitheaters dürfte erst im Zuge seiner Errichtung entstanden sein, da die umgebenden Flächen keine Erhebungen oder Eintiefungen aufweisen (Abb. 5). Das Amphitheater fügte sich in seiner Orientierung in den Straßenraster von Flavia Solva: Sein Zugang im Norden erfolgte von der Straße A, die Ostflanke folgte der Straße B und im Süden führte eine Straße vom Südausgang des Theaters, einer natürlichen Terrassenkante und somit auch der Orientierung des Gebäudes XXXIV folgend, nach Südwesten ${ }^{15}$. Auf einer

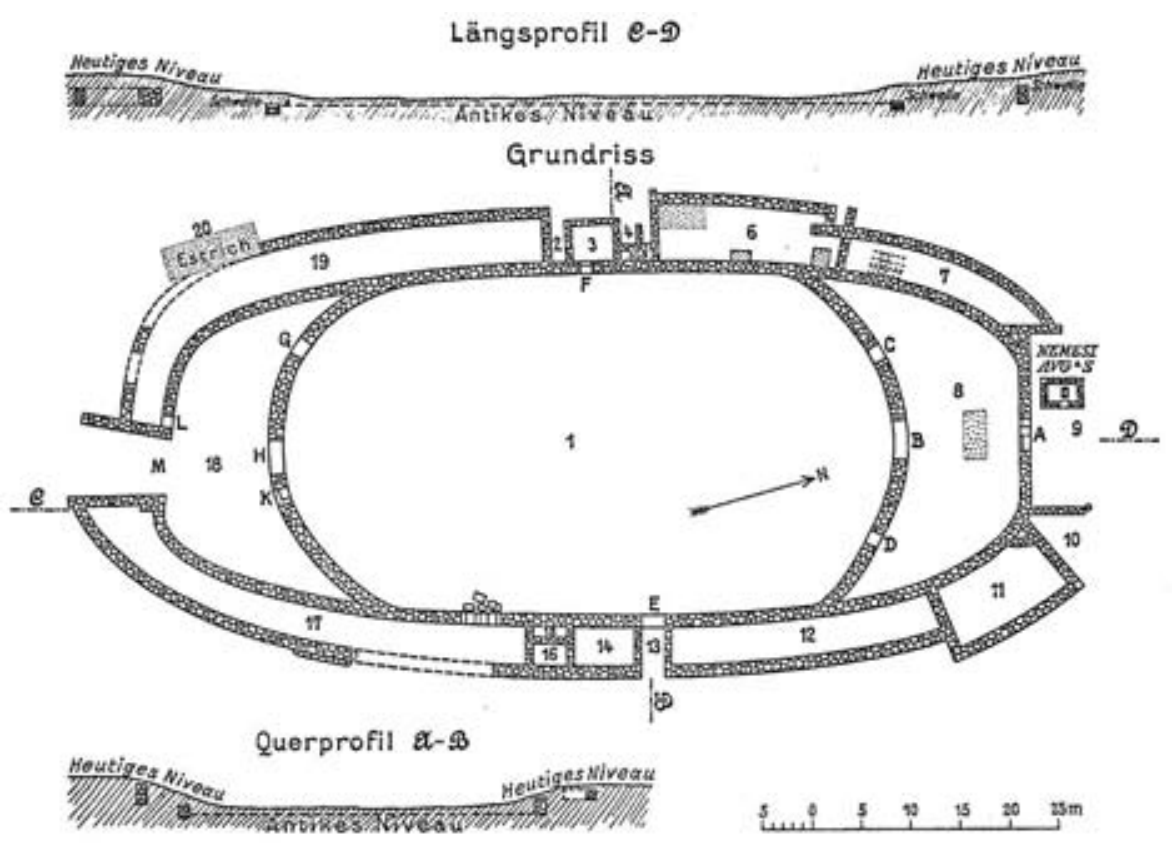

3 Das Amphitheater von Flavia Solva

\footnotetext{
${ }^{10}$ W. Artner, Die provinzialrömischen Gräber von Gleisdorf in der Oststeiermark, MUAG 38/39, 1988/89, 46 ff.

${ }^{11}$ Golvin 1988, $75 \mathrm{f}$.

12 Golvin 1988, 290 f. Taf. 54, 1.

13 Golvin 1988, 289 f. Taf. 52, 1.

14 Schmid 1919, 147 f. Abb. 61.

${ }^{15}$ Groh 1996, Plan 17. 18.
} 


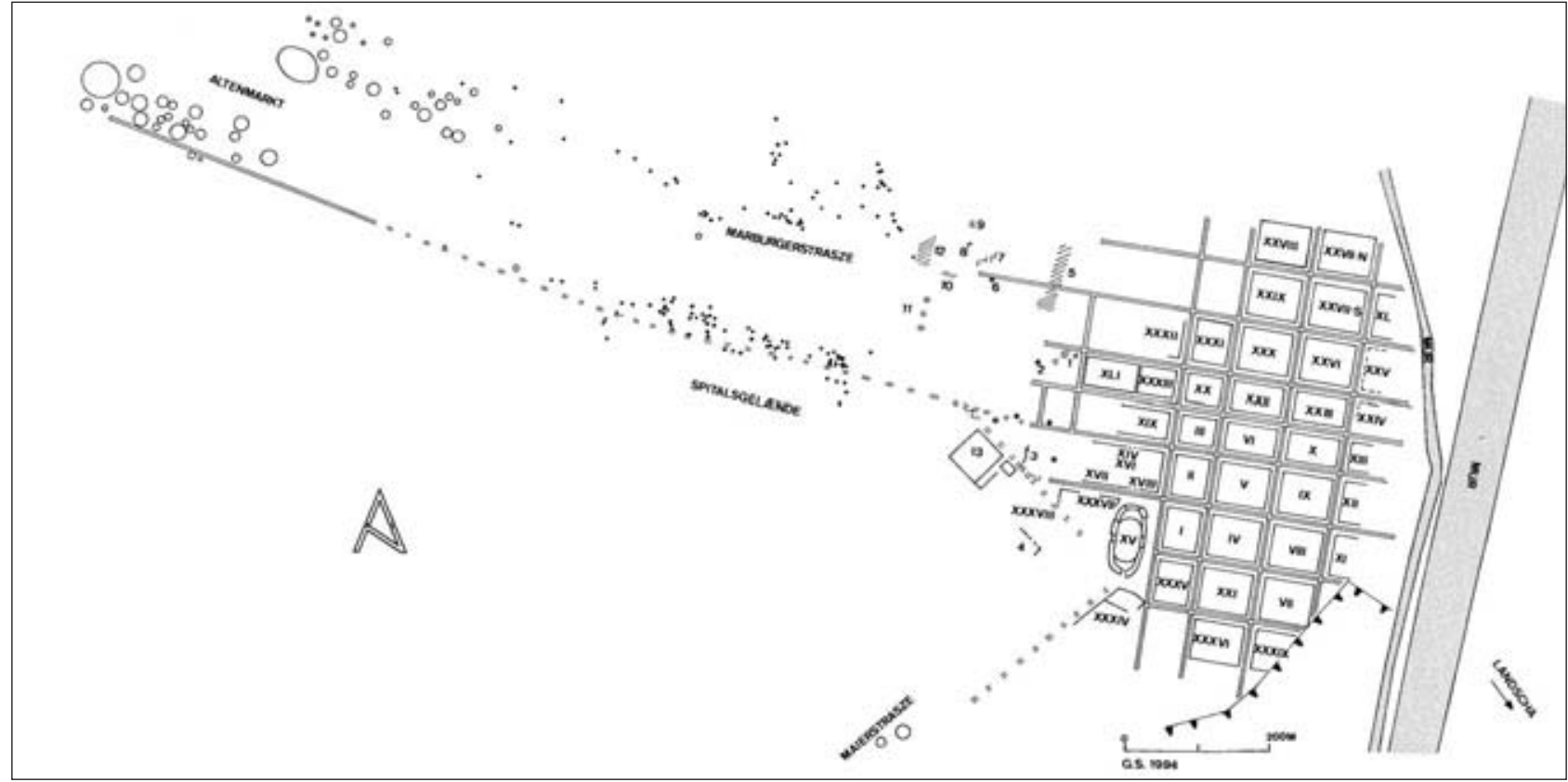

4 Stadtplan von Flavia Solva

weiteren Straße gelangte man vom westlich der Stadt gelegenen Gräberfeld (Spitalsgelände) nach Südosten zum Amphitheater, welches somit in das urbane und überregionale Wegenetz eingebunden war (vgl. Abb. 4).

Der 100,5 × 48,5 m große Bau wurde aus Sockelmauerwerk von ca. 1-1,2 m Stärke errichtet; Details der Herstellungstechnik des Mauerwerks sind nicht bekannt, da es im oberen Bereich meist abgetragen worden war. Eine Besonderheit wies die Ausgestaltung der geschotterten Arena auf, die ein inneres, axial gelegenes, $63 \times 32,7-36$ m großes Maueroval besaß. Der Ausgräber W. Schmid interpretierte den inneren Einbau, der an seinen Schmalseiten jeweils mit einem von zwei schmäleren Seiteneingängen flankierten Haupteingang versehen war, als die eigentliche Arena, das Areal zwischen den beiden Bogensegmentmauern und dem äußeren Oval aufgrund von Holzkohleresten in der nachrömischen Humusschicht (sic!) als Raum mit Holzbauten bzw. Holztribünen ${ }^{16}$. Die Hauptzugänge der äußeren Arenamauer lagen im Norden und Süden, wobei der nördliche Zugang eine Breite von lediglich ca. $3 \mathrm{~m}$ aufwies, der südliche hingegen mit flankierendem Mauerwerk 5,8 m breit war. Die Breite der Cavea differierte von 5,2-6,2 m, lag im Mittel bei ca. 6 m, wobei keine regelmäßig angeordneten radialen Stützmauern nachzuweisen waren. Im Bereich des Südeingangs wurde an der Ostseite die südliche Begrenzungsmauer der Cavea gegenüber jener im Westen deutlich vorgezogen, die Cavea war hier 8,9 m breit - gegenüber einer Breite von 5,2 m an der Westflanke. Im Mittelbereich der Cavea waren sowohl im Westen als auch im Osten mehrere Kammern eingebaut, der Nordteil besaß sowohl im Osten als auch im Westen eine grobe Gliederung in jeweils zwei Abschnitte. Westlich des Nordeingangs wurde ein 3,9 × 2,9 m großer Raum mit Steinsockelmauerwerk freigelegt, der anhand einer "nicht weit von der Schwelle des nördlichen Haupteinganges auf der Außenmauer " gefundenen, der Nemesis geweihten Ara als Nemesisheiligtum interpretiert wurde ${ }^{17}$. Über die Ausstattung des Theaters lassen sich nur wenige Angaben machen, einzig mehrere Marmorplatten(-fragmente?) könnten von einer Verkleidung der inneren Caveamauern stammen. Die Anlage des Solvenser Amphitheaters wurde von W. Schmid allein auf-

16 »... die Räume zwischen dem Bogen und dem äußeren Ovalsegment waren, wie aus der nachrömischen, mit Holzkohlenresten sehr stark durchsetzten Humusschichte ersichtlich ist, mit einem Holzbau versehen.« (Schmid 1919, 148).

17 Unklar ist, ob der Ausgräber sich bezüglich des Fundortes der Votivara (Weber 1969, 153) auf die Außenmauer des Amphitheaters oder aber des 'Nemsisheiligtums' bezieht. Wahrscheinlicher ist eine Lage auf der Außenmauer des Amphitheaters in Phase 2, da der rechteckige Bau nordwestlich des Eingangs keine Innenmauer aufweist. Eine Ortsangabe mit »nicht weit der Schwelle des nördlichen Haupteinganges auf der Außenmauer« erscheint daher unlogisch, obwohl in der nachfolgenden Literatur der Fundort mit dem kleinen Rechteckbau gleichgesetzt wurde (Hudeczek 1979, 457). 
grund seiner auf dem damaligen Stand der Forschung basierenden Stadtentwicklungstheorie in das 3. Jahrhundert $\mathrm{n}$. Chr. datiert ${ }^{18}$.

Die Grundrissgestaltung der Arena mit zwei Caveamauern, wie dies der Ausgräber für einen Bauzustand vorschlug, ist äußerst ungewöhnlich und sucht ihresgleichen in den römischen Provinzen. Nach der Auffassung von W. Schmid nutzte man den Bereich zwischen dem inneren Oval und der Cavea als Tribüne oder als Raum für »Kulisseneinbauten oder Garderobenräume«, ein Baudetail, für das es keine typologischen Vergleichsbeispiele gibt. Die Grundrissgestaltung der beiden Ovale und die Anordnung axial gelegener Eingänge unterschiedlicher Breite im inneren und äußeren Oval lassen auf die Existenz zweier Amphitheater schließen: eines kleineren Vorgängerbaus mit einer Cavea ohne Stützmauern und einer Erweiterung in einer zweiten Bauphase mit einer größeren Arena, einer Cavea mit Stützmauern und Einbauten sowie einer Verbreiterung der südlichen Toranlage ${ }^{19}$. Die Fundamentmauern der inneren Arena der Phase 1

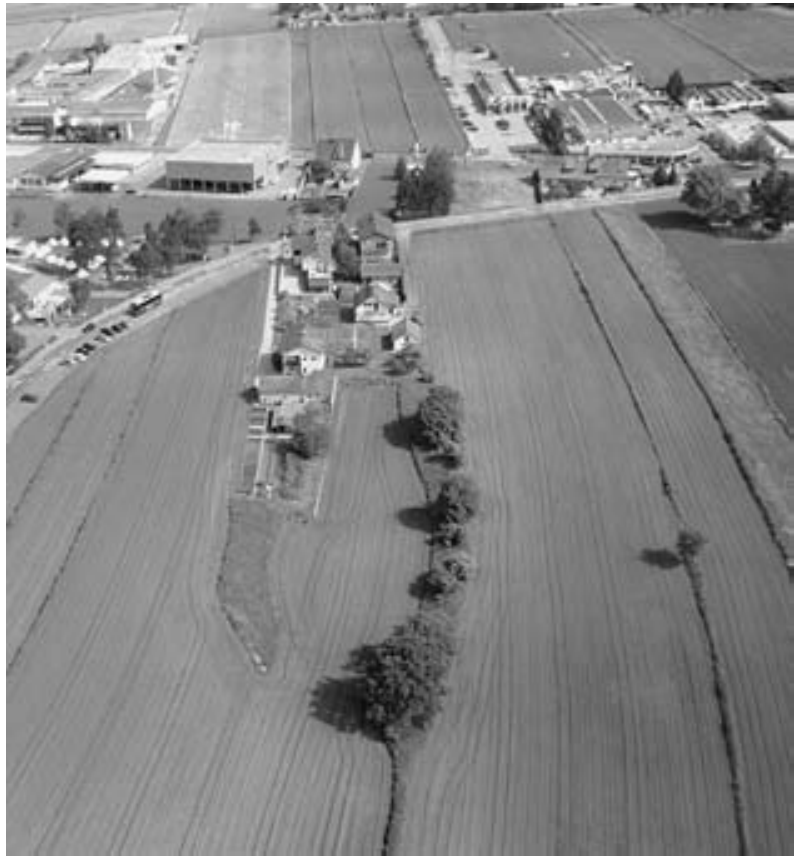

5 Das Amphitheater von Flavia Solva, Blick von Süden (2004) waren deutlich tiefer fundamentiert und weniger hoch erhalten als jene der größeren Arena in Phase 2 (vgl. dazu Abb. 3, Längs- und Querprofil). Während im Querprofil AB das antike Arenaniveau an der Unterkante der Begrenzungsmauer ansetzte, zog es im Längsprofil CD zu den Oberkanten der nördlichen und südlichen Begrenzungsmauern bzw. Türschwellen, d. h., in Phase 2 schleifte man die Fundamentmauern der nördlichen und südlichen Bogensegmentmauern bis auf Höhe des neuen höheren Arenabodens in Phase 2. Die von W. Schmid beobachteten Holzkohlelagen zwischen der inneren Arenamauer und der äußeren Bogensegmentmauer könnten, als verbrannte Reste der hölzernen Tribünen interpretiert, die Aufgabe des ersten Amphitheaters anzeigen. Die Grundrissgestaltung des Amphitheaters in Phase 2 bezeugt eine Verlegung des Hauptzugangs nach Süden, wo man die Toranlage auf annähernd doppelte Weite vergrößerte. Zur selben Zeit errichtete man im nördlich gelegenen Eingangsbereich einen als Nemeseum interpretierten Bau.

Mit 63 × 32,7-36 m Größe und einem längsrechteckig-ovalen Grundriss wies das Theater in Phase 1 starke Affinität zu den Theatern in Carmo (Carmona) und Emporiae (Ampurias) sowie zu den etwas kleineren in Virunum, Luceria (Lucera) und Caesarea (Cherchel) auf ${ }^{20}$. Es kann nicht ausgeschlossen werden, dass der Bau in Phase 1 eine stärker an ein Oval angelehnte Form besessen hatte und somit dem Theater in Gleisdorf

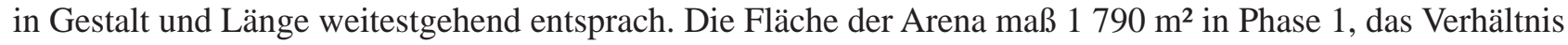
der Längsachse a zur Achse b betrug 1,72, womit diese Arena bereits im Bereich der langgestreckten Formen anzusiedeln ist.

In Phase 2 war das Amphitheater mit seiner längsovalen Form jenen von Virunum und Caesarea sehr ähnlich. Die Gesamtfläche des neuen Amphitheaters betrug $3950 \mathrm{~m}^{2}$. Die Arena dieses in der Ebene errichteten Theaters wurde, wie wahrscheinlich auch die der Phase 1, teilweise in die Erde eingetieft und mit

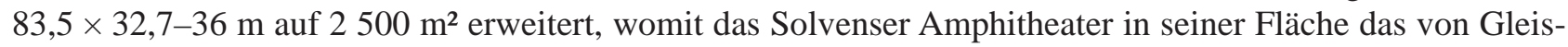
dorf übertraf. Das Verhältnis der Längsachse a zur Achse b betrug nun 2,44, die überproportional lang gestreckte Arena nahm 63\% der Gesamtfläche ein. Damit lag Flavia Solva im obersten Bereich aller bekannten

${ }^{18}$ Die anhand neuerer Grabungen und Fundvorlagen analysierte Bebauung des westlichen Stadtrands legte eine Errichtung des Amphitheaters in traianisch/hadrianischer Zeit nahe (Hudeczek 1979, 455 ff.; Groh 1996, 178) - dem Datierungsansatz von W. Schmid folgte jedoch zuletzt noch H. Dolenz (Dolenz 2004, 320 Anm. 177).

${ }^{19}$ E. Diez stellte bereits 1946 eine Zweiphasigkeit des Amphitheaters von Flavia Solva zur Diskussion, ging jedoch von einem ersten, größeren Bau und einem zweiten, verkleinerten Amphitheater im ausgehenden 2. bzw. 3. Jh. n. Chr. aus. Die Errichtung des ersten Baus setzte sie in hadrianisch/antoninische Zeit (E. Diez, Ein Nemsis-Relief aus Flavia Solva, ÖJh 36, 1946, 11).

${ }^{20}$ Golvin 1988, Taf. 7, 5 (Carmona), Taf. 17, 7 (Ampurias), Taf. 8, 5 (Lucera), Taf. 29 (Caesarea). 
Amphitheater der römischen Provinzen, was eindeutig eine Fokussierung auf die Arena und die Ausrichtung besonderer Spiele, nicht aber auf die größtmögliche Besucherzahl erkennen lässt. Die Breite der Cavea-Substruktionen bezeugt Tribünen für 2 000-3 000 Zuseher $^{21}$.

\section{Virunum}

Der in den Jahren 1998-2001 untersuchte Bau (Abb. 6) wurde 2004 monographisch vorgelegt ${ }^{22}$. Das Amphitheater und Theater von Virunum errichtete man am Ostrand des antiken Stadtgebietes in Hanglage, die Nord-Süd-Achse des Amphitheaters folgte dabei nicht der des orthogonalen Straßenrasters, sondern den topographischen Voraussetzungen (Abb. 7 Nr. 17). Die lokale verkehrstechnische Erschließung bzw. Einbindung von Theater und Amphitheater in den Straßenraster ist nicht geklärt; das Amphitheater kam zwischen Forum und Statthalterpalast zu liegen. Die Grundkonzeption der 108,1 $\times$ 46,5 m großen, auf einer artifiziellen Hangterrasse errichteten Anlage geht in hadrianische Zeit zurück (terminus post quem $131 \mathrm{n}$. Chr.), weitere Umbauphasen, die jedoch an der grundlegenden Gestalt des Amphitheaters kaum Änderungen bewirkten, erfolgten noch im ausgehenden 2. Jahrhundert n. Chr. mit der Erweiterung des Nordtors und der Aufgabe des unterirdischen Zugangs in die Arena. Im 3. Jahrhundert n. Chr., nach einem Großbrand in severischer Zeit, nahm man Aufplanierungen im Cavea-Oval und Erneuerungen der Holztribünen und der Toranlagen (237 n. Chr.) vor sowie, nach einem weiteren Großbrand in den 70er Jahren des 3. Jahrhunderts n. Chr., eine erneute Aufplanierung der Cavea. Ausbesserungsarbeiten führte man am Nemeseum durch, darüber hinaus erfolgten ein Neubau der Tribünen und die Aufgabe des Kanalsystems und zahlreicher Zugänge. Anhand von Einplanierungen im Nemeseum ist die intentionelle Aufgabe für konstantinische Zeit belegt.

Das Amphitheater wies keine vollkommen regelmäßige Form auf, der Grundriss verjüngte sich - bedingt durch die Verschmälerung der Geländeterrasse - nach Norden. Der Abstand der inneren Cavea-Mauern betrug im Süden 32,5 m, im Norden 30,5 m, der südliche Halbkreis besaß einen Radius von 16,5 m. Die Arena war demnach 93,7 m lang und (im Mittel) 31,6 m breit. Im Zuge der Grabungen wurden ca. 60\% der Cavea, das Nord- und Südtor, ein im Mittelteil der Arena gelegener, unterirdischer Gang und zwei Kanäle freigelegt; der Großteil der Arena blieb jedoch von archäologischen Untersuchungen unberührt. Die Substruktionen der Cavea bestanden aus je einem im Abstand von 4,5-5 m annähernd parallel verlaufenden, ca. 0,6 m breiten, inneren und bis zu 1,2 m breiten, äußeren Mauerring aus Bruchsteinen in Kalkmörtel. Zwischen diesen beiden Mauern waren im Abstand von ca. 2,5 m Radial- bzw. Quermauern angebracht. Im Bereich des Süd- und

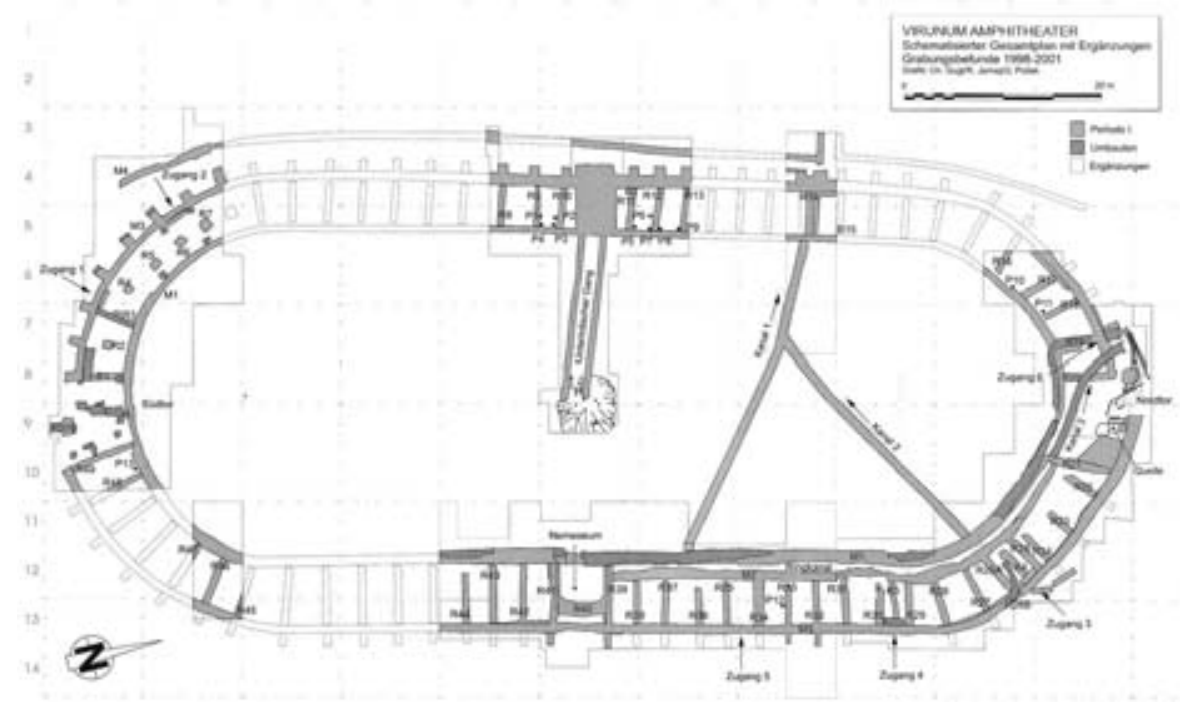

6 Das Amphitheater von Virunum
Nordtors wurden die äußere Begrenzungsmauer der Cavea und damit verbunden die Radialmauern, vergleichbar mit der Situation in Flavia Solva, um ungefähr jeweils 1,5-2 m nach außen vorgezogen; die Cavea besaß hier eine Breite von ca. 8,2 m im Süden und 9,2 m im Norden. In der Mitte der östlichen Cavea errichtete man gegenüber dem Eingang zu dem unterirdischen Gang einen 4,84 × 5,9 m großen, von der Arena aus zu betretenden Raum, der als Nemeseum interpretiert werden konnte.

${ }^{21}$ Vgl. Golvin 1988, Taf. 70, 4 bzw. Taf. 53, 2.

22 Jernej 2004, 48 ff. 
7 Stadtplan von Virunum

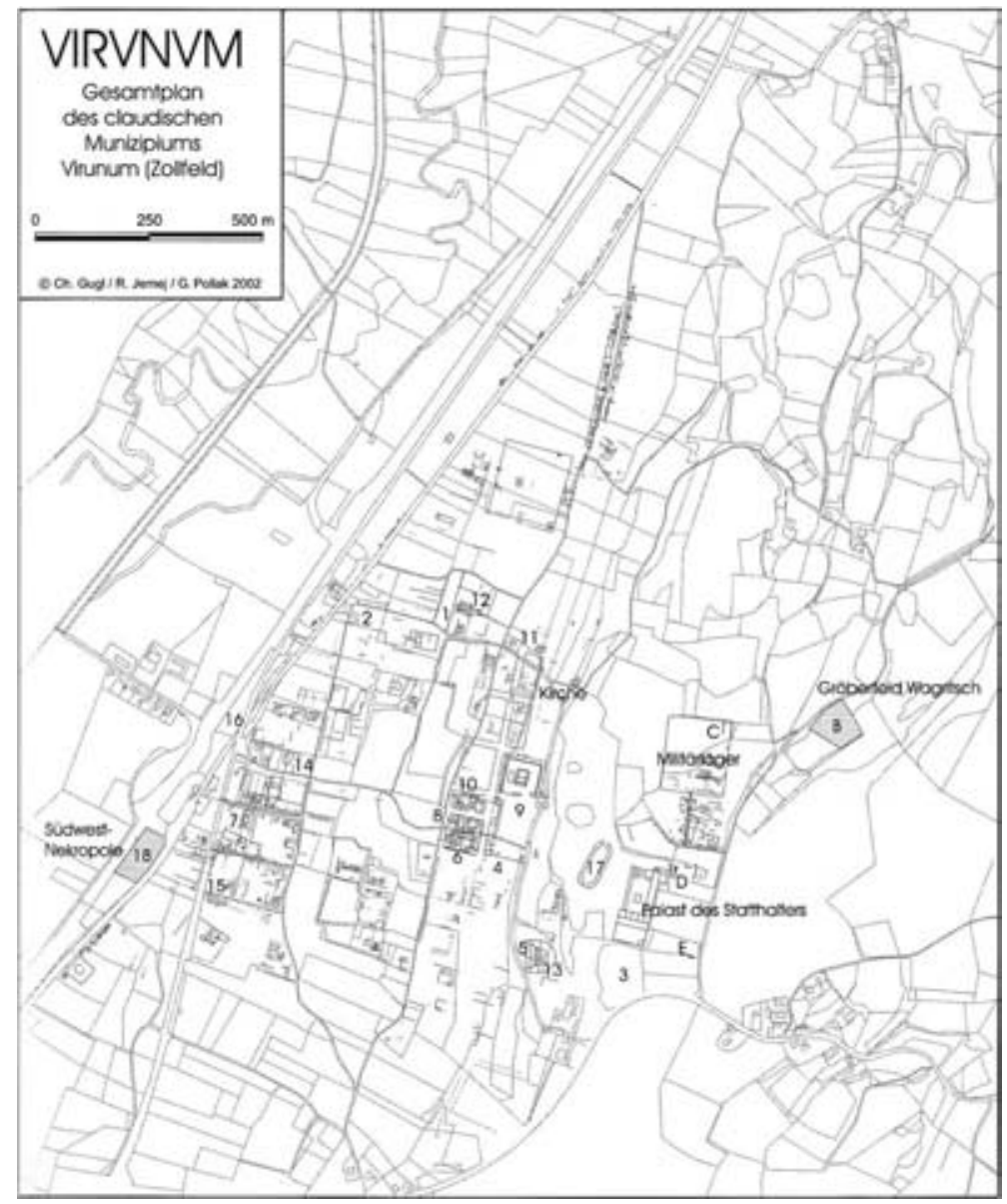

Das Amphitheater von Virunum entspricht dem von J.-C. Golvin definierten Typ 1b, dessen Zuschauertribünen von einer Konstruktion aus Umfassungsmauern und radialen Stützmauern getragen wurden. Hinsichtlich seines Bautyps lässt es sich am besten mit den Amphitheatern aus Caesarea (Cherchel), Luceria (Lucera) und Flavia Solva vergleichen ${ }^{23}$. Bei der Errichtung der Cavea und der Tribünen nutzte man die Hangneigung im Westen und musste nur im Osten höhere Fundamentmauern aufziehen ${ }^{24}$. Mit 2740 m² bedeckte die Arena 57\% der Gesamtfläche (4 $800 \mathrm{~m}^{2}$ ) des Amphitheaters, was, vergleichbar mit Flavia Solva, einen Spitzenwert darstellt. Das Verhältnis der Längsachse a zur Achse b betrug 2,97, womit die Arena als die am längsten gestreckte und zugleich schmalste der römischen Welt betrachtet werden kann und noch deutlich über der Arena von Flavia Solva in Phase 2 mit dem Koeffizienten 2,44 zu liegen kommt. Auch hinsichtlich der Zuschauerränge dürfte der Bau von Virunum mit einem Fassungsvermögen von 3000-4 000 Personen jenen von Flavia Solva übertreffen.

\section{Die municipalen Amphitheater von Virunum und Flavia Solva im Vergleich}

Die Amphitheater von Virunum und Flavia Solva entsprechen mit Steinsubstruktionen der Cavea für die Tribünen dem Bautyp 1b nach Golvin (Abb. 8). Geht man davon aus, dass in der Provinzhauptstadt das erste monumentale Amphitheater errichtet wurde, so wäre es sicherlich Vorbild für die übrigen Bauten gewesen, die innerhalb der Provinz auf den Südosten beschränkt waren.

\footnotetext{
${ }^{23}$ Golvin 1988, 113 Taf. 29 (Caesarea), Taf. 8, 5 (Lucera) und Jernej 2004, 48 sowie Dolenz 2004, 273.

24 Vgl. Golvin 1988, Taf. 70, 5.
} 


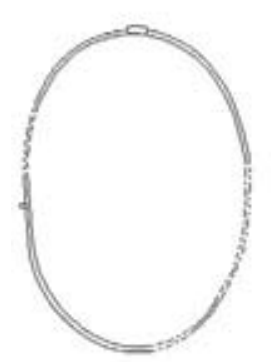

1

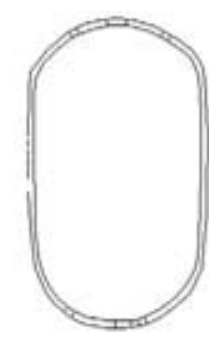

2

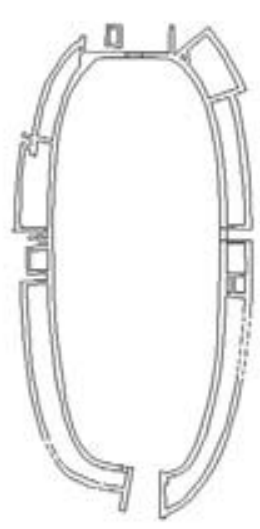

3

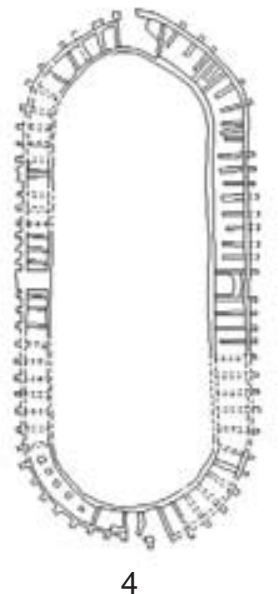

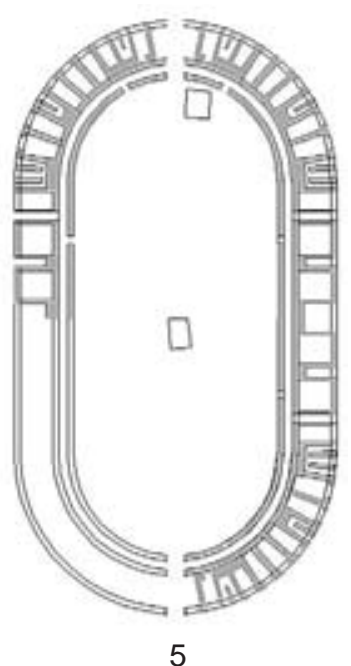

8 Amphitheater in Noricum im Vergleich mit dem Amphitheater von Caesarea (Mauretania): 1 Gleisdorf, 2 Flavia Solva (Phase 1), 3 Flavia Solva (Phase 2), 4 Virunum, 5 Caesarea

Das Amphitheater von Virunum folgte in seiner Grundrissgestaltung nicht den nahe gelegenen Bauten der regio $X$ (z. B. Aquileia) oder Pannoniens (z. B. Scarbantia, Carnuntum) ${ }^{25}$, sondern entsprach gleichsam einer verkleinerten Kopie dem von Caesarea (Cherchel) in der Provinz Mauretania Caesarensis ${ }^{26}$. Der Arena des Amphitheaters von Caesarea war ein Rechteck von $57 \times 44 \mathrm{~m}$ eingeschrieben, dem man an den Schmalseiten zwei Halbkreise mit einem Radius von 21,5 m anfügte. Die Arena von Virunum setzte sich aus einem leicht trapezförmigen Rechteck von 68 × 30,5-32,5 m mit Halbkreisen von 16,25 m Radius zusammen. Die Längen und Breiten der eingeschriebenen Rechtecke in Caesarea und Virunum verhielten sich wie 1,3:1 bzw. 2,2:1, was einer unproportionalen Adaption des in Caesarea vorgegebenen Bautyps in Virunum entsprach. Beide Bauten waren mit einem unterirdischen Gang zu einem mittig in der Arena gelegenen Einbau ausgestattet.

Die Solvenser Arena der ersten Bauphase war eine verkürzte Kopie der Arena von Virunum. Geht man davon aus, dass das Solvenser Amphitheater in Phase 1 - wie jenes in Gleisdorf - nur aus dem Längsoval der Arena und einer Erdaufschüttung für die Tribünen bestanden hat, so fällt auf, dass das Längsoval mit einer Breite von 32,7 m und dem Krümmungsradius des südlichen Halbkreises von 16 m dem der Arena von Virunum entsprach, die Arena insgesamt jedoch mit $62 \mathrm{~m}$ Länge um ein Drittel kürzer angelegt worden ist. Charakteristisch für alle drei Amphitheater war eine überproportional große Arena, deren Fläche rund $60 \%$ des gesamten Baus einnahm (Tab. 1).

Tab. 1: Maßzahlen der norischen Amphitheater von Virunum, Flavia Solva und Gleisdorf im Vergleich mit Caesarea (Abb. 8)

\begin{tabular}{|c|c|c|c|c|c|c|c|c|}
\hline Amphitheater & Тур & $\begin{array}{c}\text { Länge } \times \text { Breite } \\
(\mathrm{m})\end{array}$ & $\begin{array}{c}\text { Umfang } \\
\text { (m) }\end{array}$ & $\begin{array}{c}\text { Fläche } \\
\left(\mathrm{m}^{2}\right)\end{array}$ & $\begin{array}{c}\text { Fläche } \\
\text { Arena } \\
\left(\mathbf{m}^{2}\right)\end{array}$ & $\begin{array}{c}\text { Länge a } \\
\text { Arena } \\
\text { (m) }\end{array}$ & $\begin{array}{c}\text { Breite b } \\
\text { Arena } \\
\text { (m) }\end{array}$ & $\frac{\mathbf{a}}{\mathbf{b}}$ \\
\hline Virunum & $1 b$ & $108,1 \times 46,5$ & 274 & 4800 & 2740 & 93,7 & $30,5-32,5$ & 2,97 \\
\hline $\begin{array}{l}\text { Flavia Solva, } \\
\text { Phase } 1\end{array}$ & $1 \mathrm{a}$ & $63 \times 32,7-36$ & $\begin{array}{c}169 \\
\text { (Arena) }\end{array}$ & & 1790 & 62 & $32,7-36$ & 1,72 \\
\hline $\begin{array}{l}\text { Flavia Solva, } \\
\text { Phase } 2\end{array}$ & $1 \mathrm{~b}$ & $100,5 \times 48,5$ & 250 & 3950 & 2500 & 83,5 & $32,7-36$ & 2,44 \\
\hline Gleisdorf & 1a & $\begin{array}{l}66 \times 46 \\
(\text { Arena) } \\
\end{array}$ & $\begin{array}{c}180 \\
\text { (Arena) }\end{array}$ & & 2250 & 65 & 45 & 1,44 \\
\hline Caesarea & $1 \mathrm{~b}$ & $\begin{array}{c}124 \times 67 \\
(134 \times 77)\end{array}$ & 319 & 7000 & 4028 & 101 & 44 & 2,3 \\
\hline
\end{tabular}

\footnotetext{
${ }^{25}$ G. Mansuelli, Urbanistica e architettura della Cisalpina romana fino al III sec. e.n., Collection Latomus 111 (1971) 5 ff.; Golvin 1988, Taf. 17, 5 (Aquileia), Taf. 14, 6 (Carnuntum); Gömöri 1994, 257 Abb. 3 (Scarbantia).

${ }^{26}$ Golvin 1988, 112 ff. Taf. 29, 1 und Golvin - Leveau 1979, 817 ff.
} 


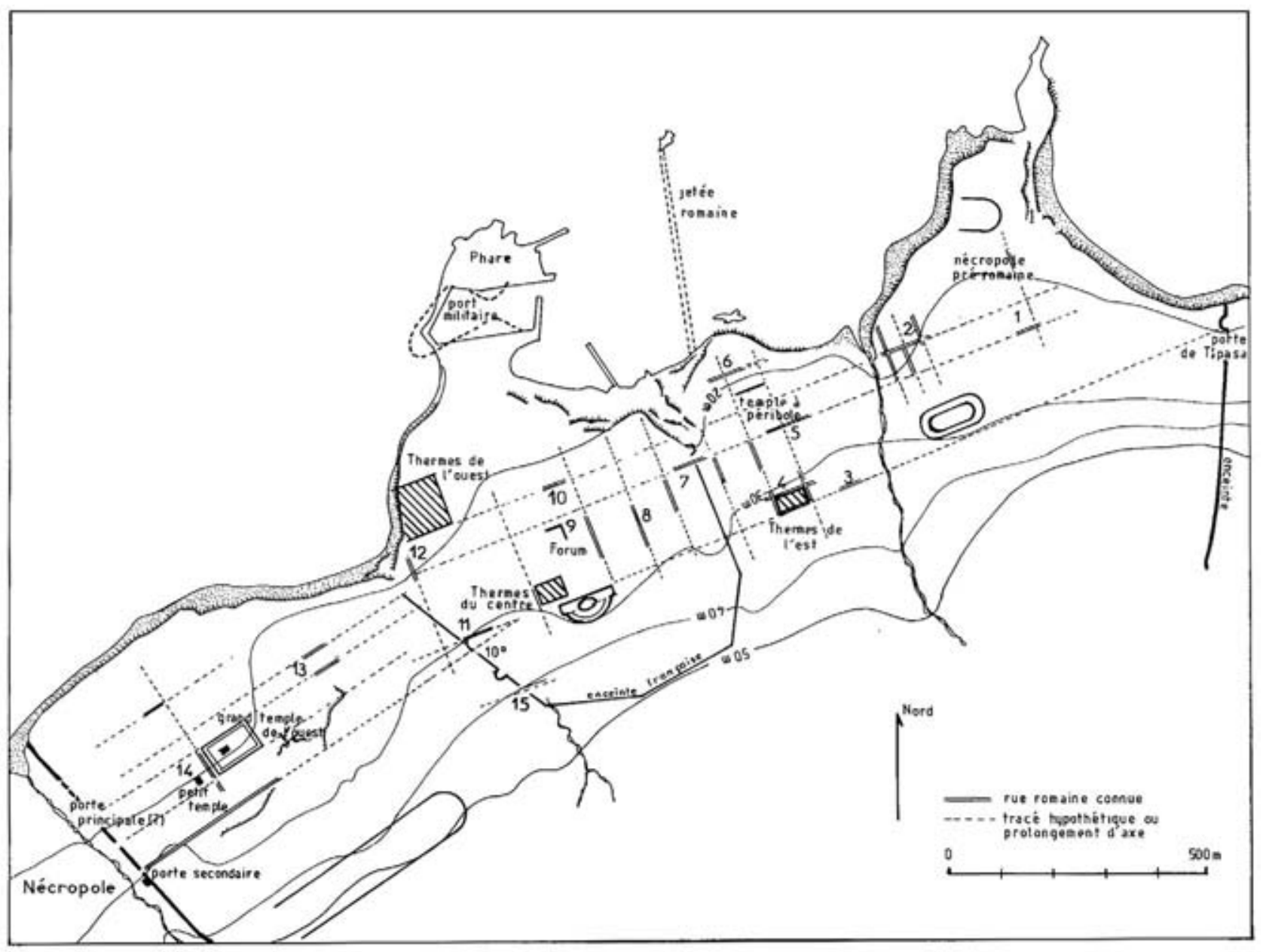

9 Stadtplan von Caesarea Mauretania

Beachtenswert erscheint auch die mit Virunum vergleichbare topographische Lage von Caesarea, das an seiner dem Meer abgewandten Südflanke von einer Hügelkette begrenzt wird, in deren Ausläufer sowohl das Amphitheater als auch das Bühnentheater gebaut wurden (Abb. 9) ${ }^{27}$. Zwischen dem Amphitheater von Caesarea und dem in hadrianische Zeit datierten Bühnentheater von Virunum ist ein weiterer Bezug festzustellen $^{28}$ : Das Bühnentheater von Virunum entsprach einem Bau italischen Typs, wobei die beiden parascaenia überproportional groß angelegt worden waren; das südliche schließt sogar das postscaenium mit ein (Abb. 10). Die überdimensional große Ausgestaltung der beiden parascaenia zu basilicae lässt sich bereits im Theater des Marcellus in Rom und in der spätaugusteischen Anlage von Orange beobachten und ist für viele italische Bauten, auch für das Theater von Triest, belegt ${ }^{29}$. Die Cavea des Virunenser Bühnentheaters besaß einen Durchmesser von 70 und einen Radius von 35 m, womit sie auffallend mit den beiden Halbrunden des Amphitheaters von Caesarea in seiner ersten Bauphase von jeweils $67 \mathrm{~m}$ Durchmesser übereinstimmt ${ }^{30}$.

Die planimetrische Anlage der Hauptstadt Virunum mit einem orthogonalen Straßen- und Gebäuderaster orientierte sich am Verlauf einer überregionalen, das Stadtgebiet in nord-südlicher Richtung querenden Straße (vgl. Abb. 7). Im Bereich des Forums und des Kapitols wurden zwei schmale, die Hauptachse flankierende Gebäudereihen zusammengelegt. Die Urbanisierung oder Stadtgründung um die Mitte des 1. Jahrhunderts

${ }^{27}$ Golvin - Leveau 1979, 818 ff. Abb. 1, 3.

${ }^{28}$ Das Theater von Virunum wurde bereits 1855 entdeckt und 1926-30 untersucht: R. Egger, Aus dem römischen Kärnten, Carinthia I 128, 1938, 14 ff. und Piccottini 1989, 176 ff.

${ }^{29}$ Gros 1996, $288 \mathrm{ff}$.

${ }^{30}$ Das Amphitheater von Caesarea maß in seiner ursprünglichen Größe $124 \times 67$ m und wurde in einer zweiten Phase im Bereich der Cavea auf $134 \times 77 \mathrm{~m}$ erweitert (Golvin 1988, 113). 

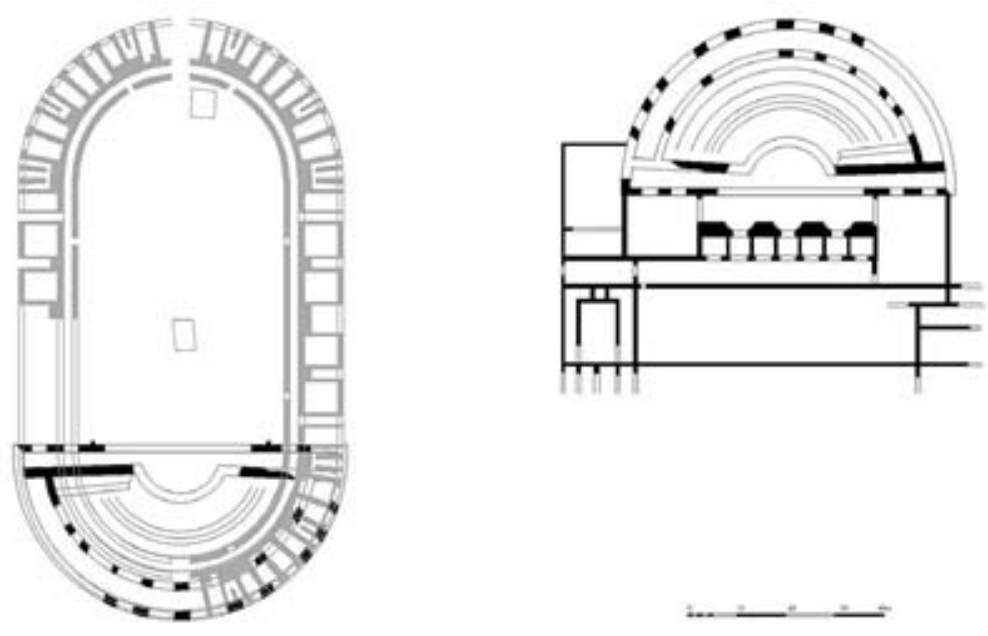

10 Das Amphitheater von Caesarea und das Theater von Virunum n. Chr. führte zu infrastrukturellen Baumaßnahmen, das einheitliche urbanistische Konzept wurde jedoch in den ersten Jahrzehnten nach der Stadtgründung nicht zur Gänze umgesetzt. Die erste Bauphase der in unmittelbarer Nähe südwestlich des Forums gelegenen Insula I wird um die Mitte des 1 . Jahrhunderts $n$. Chr. angesetzt ${ }^{31}$, am westlichen Stadtrand erfolgte die reguläre Bebauung jedoch erst um die Mitte des 2. Jahrhunderts n. Chr. ${ }^{32}$. Die öffentlichen Gebäude, das Forum mit dem Tempelbezirk, das Amphitheater, das Theater und der Statthalterpalast befanden sich im Ostteil der Stadt auf drei Geländestufen. Zuunterst in der

Ebene lagen das wirtschaftliche und religiöse Zentrum, auf einer erhöhten Terrasse errichtete man den Statthalterpalast und dazwischen - die topographischen Gegebenheiten nutzend - das Amphi- und das Bühnentheater.

Die Anlagen des Forums und Tempelbezirks sowie des Statthalterpalastes der claudischen Provinzhauptstadt sind wohl vor den Bau der beiden Theater zu setzen ${ }^{33}$; diese dürften demnach die letzte größere kaiserzeitliche Ausbaustufe mit Repräsentationsbauten des ursprünglichen urbanistischen Konzepts darstellen. Im selben inhaltlichen und zeitlichen Kontext könnte auch der Ausbau des suburbanen Tempelbezirks in einem Vicus nördlich von Virunum bei St. Michael am Zollfeld mit einem an städtische Fora bzw. Kaiserfora erinnernden Grundriss stehen, der anhand stratigraphischer Evidenzen von H. Dolenz in die Zeit nach 100 n. Chr. datiert wird ${ }^{34}$.

Einfache Amphitheater, wie jenes von Flavia Solva in Bauphase 1 und Gleisdorf, wurden, im Gegensatz zu repräsentativen Anlagen im urbanen Umfeld, meist außerhalb der Siedlungen und Gräberfelder in einer topographisch geeigneten Lage, z. B. in einer natürlichen Senke, errichtet. Dies könnte auch der Grund für die Ausführung des ersten, bloß aus einer steinumfassten Arena bestehenden Amphitheaters von Flavia Solva gewesen sein. Die früheste Bautätigkeit innerhalb des im 1. Jahrhundert n. Chr. angelegten, schachbrettartigen Straßenrasters des Municipiums beschränkte sich nach derzeitigem Wissensstand auf zentrale Gebäudeblöcke (z. B. Insula XXII). Die vom Zentrum entfernten Gebiete oder Parzellen dürften mehrheitlich erst im 2. Jahrhundert n. Chr. verbaut worden sein (vgl. Abb. 4) 3. $^{35}$ Das Bauland für das Amphitheater wurde von Beginn an parzelliert und lag ursprünglich im Südwesten außerhalb der Stadt am Verlauf zweier Ausfallstraßen. Somit besaß der Bau in Phase 1 sicherlich noch keinen hohen repräsentativen Charakter. Die wachsende Prosperität des Municipiums und der damit verbundene Bevölkerungszuzug verlangten wohl nach einer Vergrößerung des Amphitheaters. Es bezeugte in seiner zweiten Ausbauphase durch die Verbreiterung der Cavea im Bereich der beiden Hauptausgänge, die Größe und Positionierung von rechteckigen Bauten im Mittelbereich der Cavea (Nemeseum) und in seiner Dimensionierung der Arena, deren Form und endgültige Größe (83,5 × 32,7-36 m)

${ }^{31}$ Piccottini 1989, $173 \mathrm{ff}$.

32 Dolenz 2004, 320; vgl. dazu die bereits oben erwähnte Stadtentwicklung des Municipiums Flavia Solva, wo im Bereich der Insula XLI am westlichen Stadtrand die Bebauung erst in traianischer Zeit einsetzte (Groh 1996, 174 ff.).

33 Zuletzt zu Forum und Tempelbezirk E. M. Luschin, Das Stadtzentrum von Virunum, ÖJh 72, 2003, 149 ff., der als Vorbilder für das in Virunum verwirklichte Konzept die Anlagen von Aosta, Emona, Pola, Augst, Martigny und Nyon anführt. Mit C. Baebius Atticus ist der erste namentlich bekannte norische Prokurator in claudischer Zeit gegeben (Winkler 1969, 30).

${ }^{34}$ H. Dolenz, Die Ausgrabungen im Tempelbezirk St. Michael am Zollfeld im Jahr 2002, Rudolfinum. Jahrbuch des Landesmuseums Kärnten 2002, 132 ff.

35 z. B. Insulae XXX und XXXI am Nordrand, Insula XLI am Westrand und Insulae XXVII und XLIII am Südrand der Stadt (Groh 1996, 174 ff. bzw. H. Heymans, Vorläufiger Bericht zu den neuen archäologischen Notgrabungen 'Am Hochweg' am südlichen Stadtrand von Flavia Solva, MblFlavSolv 1, 2003, 6 ff.). 
nur mehr wenig von der des Virunenser Amphitheaters (93,7 × 30,5-32,5 m) abwich, erneut eine enge Verwandtschaft zu diesem. Die Ähnlichkeiten gehen weit über Zufälligkeiten hinaus, zumal der Bautyp mit einer langgestreckten, annähernd rechteckigen Arena mit Halbkreisen an sich schon eine Ausnahme in den römischen Provinzstädten darstellt; erinnert sei an dieser Stelle nur an das einzigartige Verhältnis der Längs- und Breitenachse a:b der Virunenser Arena von 2,97. Die Vergrößerung der Arena um ein Drittel und die Errichtung von Substruktionen und Kammern in der Cavea des Solvenser Amphitheaters erfolgten in direkter Anlehnung an das Virunenser Vorbild. Die Anlage des ersten Amphitheaters in Flavia Solva dürfte aufgrund der Analogien zum Virunenser Bau in hadrianische Zeit zu setzen sein, wobei wohl mit einer raschen Ausbreitung der Stadt bis in ihre Randbezirke und dem damit verbundenen Ausbau des Amphitheaters zu einem repräsentativen urbanen Bauwerk noch in hadrianisch/antoninischer Zeit zu rechnen ist. Diese Datierungsansätze unterstützen auch die chronologische Einordnung des im Bereich des nördlichen Amphitheatertors bei dem als Nemeseum interpretierten Bau angetroffenen Nemesis-Weihealtares des Canius Tertullinus in die zweite Hälfte des 2. Jahrhunderts n. Chr. und eines weiteren Weihealtares für die Göttin Nemesis aus Sekundärverwendung ab der Mitte des 2. bis an den Anfang des 3. Jahrhunderts n. Chr. ${ }^{36}$. Für die Aufgabe des Amphitheaters von Flavia Solva liegen keine Evidenzen vor.

\section{Das Amphitheater des Vicus von Gleisdorf im Vergleich}

Die Arena des Amphitheaters von Gleisdorf wies gegenüber Virunum und Flavia Solva eine unregelmäßigere und ovalere Gestalt auf (vgl. Abb. 8). Zerlegt man die Form der Arena in ihre Einzelteile, so setzte sie sich aus zwei Halbkreisen mit einem Radius von 21,5 m und einem nicht vollständig regelmäßigen Rechteck von $22 \times 45$ m zusammen. Damit entsprachen die beiden Halbkreise der Arena jenen der Arena von Caesarea, nur das mittlere Rechteck war bei annähernd identischer Breite um 35 m kürzer als das des Amphitheaters von Caesarea $(57 \times 44 \mathrm{~m})$. Das Amphitheater von Gleisdorf war somit eine um ein Drittel verkürzte Kopie des Baus in Caesarea, das von Flavia Solva in Phase 1 wiederum eine um ein Drittel verkürzte Kopie des Amphitheaters von Virunum.

Die Abmessungen der Gleisdorfer Arena sind mit denen der Amphitheater von Carmo (Carmona), Bern, Durnovaria (Dorchester), Augusta Raurica (Augst) ${ }^{37}$ und Scarbantia (Sopron) vergleichbar ${ }^{38}$. In der nordöstlich von Gleisdorf an der Bernsteinstraße gelegenen pannonischen Stadt Scarbantia (vgl. Abb. 1) errichtete man in antoninischer Zeit nordwestlich außerhalb der Siedlung in einem steilen Hang ein Amphitheater des Typs 1b (Abb. 11). Die unregelmäßig ovale Arena von $63 \times 42 \mathrm{~m}$ Größe und einem Verhältnis der Längs- zur Breitachse von 1,5 (Gleisdorf: $65 \times 45$ m bzw. 1,44) war von einer Steinmauer umgeben, der Zugang wurde mit Toren im Norden und Süden ermöglicht. Im südlichen Zugang befand sich ein Nemeseum, die Cavea besaß eine Breite von $21 \mathrm{~m}^{39}$.

Die im Vergleich mit dem Amphitheater der unter Traian zur colonia Ulpia erhobenen Stadt Scarbantia enorme Größe des Baus im Vicus von Gleisdorf lässt sich nur mit wirtschaftlicher Prosperität und einer zentralörtlichen Funktion erklären. Man berücksichtigte bereits bei der Planung der Siedlung die entsprechenden Flächen für den Großbau, was eine von Beginn an funktionierende, differenzierte Administration des Vicus und eine lokale Nobilität voraussetzt. Die Errichtung des Amphitheaters von Gleisdorf dürfte im Zuge des von der Provinzhauptstadt Virunum ausgehenden Bauprogramms für Theaterbauten in hadrianisch/antoninische Zeit erfolgt sein. Dies erscheint auch deshalb plausibel, da für antoninische Zeit (um die Mitte des 2. Jahrhunderts n. Chr.) rege Bautätigkeit im Vicus von Gleisdorf nachzuweisen ist, deren Ziel es war, vorhandene Holzgebäude durch neue massive Steingebäude zu ersetzen. Das Ende der großflächigen Siedlungs-

\footnotetext{
${ }^{36}$ Weber 1969, 153 (Flavia Solva), 168 (Seggauberg).

${ }^{37}$ Golvin 1988, Taf. 7, 5 (Carmona), Taf. 10, 4 (Bern), Taf. 10, 2 (Dorchester), Taf. 12, 3 (Augst); die einfachen Amphitheater in Britannien lassen sich hinsichtlich Form und Bauart sehr gut mit jenem in Gleisdorf vergleichen (Fulford 1989, 177 ff.: Silchester, Maumbury, Caerwent, Circester).

${ }^{38}$ Gömöri 1994, 256 f.

39 Gömöri 1994, 256 f. Abb. 3.
} 


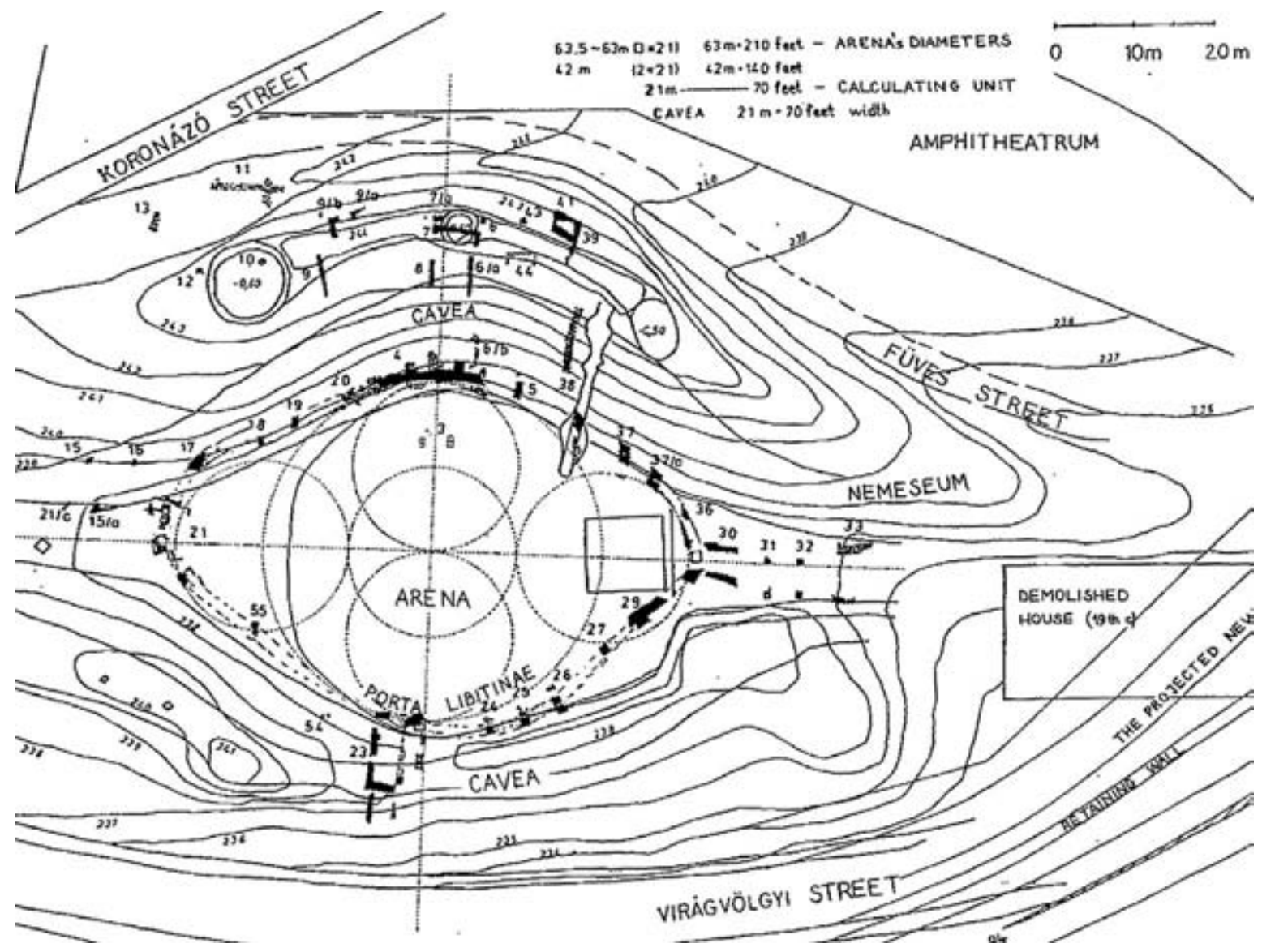

11 Das Amphitheater von Scarbantia

tätigkeit und wohl auch des Amphitheaters dürfte mit der zumindest teilweisen Aufgabe der Siedlung um oder nach der Mitte des 3. Jahrhunderts n. Chr. einhergehen ${ }^{40}$.

\section{Die Errichtung der norischen Amphitheater im historischen Kontext}

Die dargelegten Indizien sprechen für ein einheitliches Bauprogramm bei der Errichtung des Theaters und der Amphitheater von Virunum, Flavia Solva und Gleisdorf, das innerhalb eines relativ knapp bemessenen Zeitrahmens in hadrianisch/antoninischer Zeit umgesetzt worden sein dürfte. Der Ursprung für dieses Programm ist in der Provinzhauptstadt Virunum zu suchen, deren urbanistische Ausgestaltung in hadrianischer Zeit neue Impulse erhielt.

Größere Bauvorhaben öffentlicher und religiöser Gebäude in und um Virunum waren Aufgaben des jeweiligen Präsidialprokurators, wie es für den Isis-Noreia-Tempel durch eine Inschrift auf dem Ulrichsberg unter A. Trebonius (Garutianus?) in flavisch/spätflavischer und in Hohenstein unter Claudius Paternus Clementianus in hadrianischer Zeit bezeugt ist ${ }^{41}$. Folglich darf wohl auch für die Errichtung des Bühnentheaters und der Amphitheater von Virunum, Flavia Solva und Gleisdorf bzw. die Umsetzung urbanistischer Grundkonzepte der Einfluss und die Entscheidung des Präsidialprokurators von Noricum in den Jahren um oder nach 131 n. Chr. vorausgesetzt werden.

Für den in Frage kommenden Zeitraum ist C. Censorinus Niger durch zwei Inschriften als Präsidialprokurator Noricums bekannt ${ }^{42}$. Als Sohn des C. Censorius C. fil. Serenus Fl. Solva ${ }^{43}$, eines Centurios der leg.

\footnotetext{
${ }^{40}$ Maier 1995, $43 \mathrm{ff}$.

${ }^{41}$ Alföldy 1974, 81.

${ }^{42}$ CIL 5174 und 5181 (Celeia).

${ }^{43}$ CIL 1615 (Dakien).
} 
XIII gem. während der Dakerkriege, stammte er wahrscheinlich aus Noricum, und hier aus Flavia Solva. Anhand des Fragments eines Militärdiploms aus Volubilis ${ }^{44}$, das aus formalen Gründen in die Jahre 130-140 n. Chr. datiert, geht hervor, dass der Statthalter von Mauretania Tingitana das Cognomen Niger besaß; er kann wahrscheinlich mit C. Censorinus Niger identifiziert werden. C. Censorinus Niger war demnach in Noricum und Mauretania Tingitana Statthalter, wobei die chronologische Abfolge der beiden Ämter diskutiert wird: H.-G. Pflaum setzt die Prokuratur in Noricum vor jene in Mauretania Tingitana, mit dem Verweis, dass die beiden Präsidialprokuratoren S. Baius Pudens und Ti. Claudius Ti. fil. Fal. Priscianus ihre Prokuratorenämter in Mauretania Tingitana unter Marc Aurel erst nach jener in Noricum erhielten, zumal erste größere Erfahrung und Durchsetzungskraft verlangt hätte ${ }^{45}$. G. Winkler argumentiert, dass C. Censorinus Niger Nachfolger seines Freundes Gavius Maximus war, der zwischen 129 und 131 Mauretania Tingitana verwaltete, seine Statthalterschaft in Noricum somit in die Jahre nach $135 \mathrm{n}$. Chr. fallen müsse ${ }^{46}$.

Die historische Abfolge der Ämter bleibt letztendlich Ermessenssache. Fest steht nur, dass es in traianisch/hadrianischer Zeit mit Q. Ceacilius Redditus, Claudius Paternus Clementianus und C. Censorinus Niger drei norische Provinzialprokuraturen gab, die aufgrund ihrer Ämterlaufbahn enge Beziehungen zu Afrika und der Provinz Mauretania hatten ${ }^{47}$. Diese Curricula dürften beim Bau des Amphitheaters und des Theaters in der Provinzhauptstadt von entscheidender Rolle gewesen sein. Die in Virunum im Bereich des Forums und Tempelbezirks umgesetzte Kombination Tempelbezirk mit Triporticus und tiefer liegender, vorgelagerter Platzanlage mit Basilika wird von H. v. Hesberg als ein in augusteischer Zeit von dem Kaiser selbst und dessen Familie propagiertes Konzept interpretiert, welches in der jeweiligen Stadt ein neues Zeitalter symbolisieren sollte ${ }^{48}$. Bühnen- und Amphitheater könnten in der Folge als Teil eines in hadrianische Zeit zu setzenden Bauprogramms gewertet werden, mit dem man auf einen Bautyp augusteischen Ursprungs, nämlich das unter Iuba II. errichtete Amphitheater von Caesarea, zurückgriff ${ }^{49}$. Dieser Rückgriff auf ein augusteisches Bauprogramm geschah, abgesehen von funktionalen Aspekten, wohl auch vor einem ideologischen Hintergrund.

Die Rezeption des Amphitheater-Grundrisses von Virunum respektive Caesarea in Flavia Solva und Gleisdorf dürfte, wie bereits erwähnt, auch wegen der familiären Beziehungen des Prokurators C. Censorinus Niger erfolgt sein. Für die Provinz Noricum sind der Gentilnamen und das Cognomen Censorin[---], Censorinus und Censorina achtmal belegt, je dreimal im Territorium von Flavia Solva und Virunum und je einmal in dem von Celeia und Iuvavum ${ }^{50}$. Hervorzuheben ist eine Grabinschrift des 2. Jahrhunderts n. Chr. aus der Umgebung von Gleisdorf (Kaindorf), auf welcher Crispinus, Sohn einer Censorina Cetti, genannt wird, der Ädil in Flavia Solva war ${ }^{51}$.

${ }^{44}$ CIL 176 (Volubilis).

${ }^{45}$ H.-G. Pflaum, Les carrières procuratoriennes équestres sous le Haut-Empire romain (1960) 226 ff.; dieser Argumentation schließt sich G. Alfödy sowohl für Q. Caecilius Redditus als auch für C. Censorinus Niger an (Alföldy 1974, 243 f.).

46 Winkler 1969, $48 \mathrm{ff}$.

47 Alföldy 1974, 243 ff.; allgemein sind ab dem 1. Jh. n. Chr. zahlreiche, auch wirtschaftliche Kontakte zwischen Noricum und den Provinzen Afrikas bezeugt; z. B. CIL 4822 (Thubursicu Numidarum) titinia Primula origine Norica (Alföldy 1974, 122 Anm. 132) oder Händler aus Volubilis in Mauretania am Magdalensberg (Alföldy 1974, 72 Anm. 67 und S. 74 Anm. 76); das Cognomen Noricus ist in Afrika sehr geläufig (Alföldy 1974, 277).

${ }^{48}$ H. v. Hesberg, Die Monumentalisierung der Städte in den nordwestlichen Provinzen zu Beginn der Kaiserzeit, in: W. Eck H. Galsterer (Hrsg.), Die Stadt in Oberitalien und in den nordwestlichen Provinzen, Kölner Forschungen 4 (1991) 196.

${ }^{49}$ Mit dem Bau von Caesarea liegt die einzige bekannte Umsetzung der idealen geometrischen Figur eines Amphitheaters vor, wie sie von Héron von Alexandria definiert wurde (Stereometrica 1, 44; Gros 1996, 327 f.).

50 OPEL II (B. Lörincz, Onomasticon provinciarum Europae Latinarum II [1999]) 49 f.; der Name Censorinus ist mit 51 Belegen in den römischen Provinzen recht häufig, ein Schwerpunkt liegt mit 15 Belegen in der Gallia Belgica. Die Verbreitung in Noricum reflektiert auch die generelle Häufigkeit und Verteilung von Steindenkmälern mit Inschriften in der Provinz; Schlüsse auf etwaige verwandtschaftliche Beziehungen sind daher im Wissen um die Problematik der Materie und der nur in geringer Zahl zur Verfügung stehenden Materialbasis mit der gebotenen Vorsicht zu betrachten.

${ }^{51}$ Weber 1969, 85 (Kaindorf); R. Wedenig, Epigraphische Quellen zur städtischen Administration in Noricum, Aus Forschung und Kunst 31 (1997) 211 S 10; E. Weber, Das städtische Zentrum Flavia Solva und seine Beziehungen zum Hartberger Raum, ZHV Stmk 66, 1975, 37. Auf weitere familiäre Kontakte der Censorini aus Virunum nach Flavia Solva könnte ein Grabtitulus aus Arndorf hinweisen, den ein Censorinus für sich und seine Eltern Candidus und Corinthia errichten ließ, wobei seine Mutter Corinthia die Tochter des Canus war, der vielleicht mit jenem Canio, Vater des Classicanus oder Can(ius) Valentin(us) auf dem 


\section{Die norischen Amphitheater in ihrem funktionalen Zusammenhang}

Die außergewöhnlich langgestreckten, an Stadien oder römische Circusse erinnernden Grundrisse der Amphitheater von Caesarea, Virunum und Flavia Solva erlauben auch Rückschlüsse auf die Art der Spiele und Bedürfnisse sowie Traditionen der jeweiligen Provinzbewohner ${ }^{52}$.

Mauretanien war in der Antike vor allem als Lieferant wilder Tiere und Rennpferde bekannt, die bei den venationes in den Amphitheatern und den Wagenrennen in Circus und Stadion Verwendung fanden. Bereits unter Sulla führte man mauretanische Löwen für die Arena nach Italien ein ${ }^{53}$. Im Atlas und den Bergen um Septem lebende wilde Elefanten wurden militärischen und ökonomischen Zwecken dienstbar gemacht. Löwen und Panther exportierte man nach Rom, gezüchtete Pferde wurden bei der maurischen Kavallerie eingesetzt ${ }^{54}$. Anhand von Täfelchen aus der Arena des Amphitheaters von Karthago, auf denen vor allem Rinder, Wild, Bären und Löwen erwähnt werden, Mosaiken mit Tierhatzdarstellungen und Motiven auf afrikanischer Terra Sigillata wurde versucht zu zeigen, dass insbesondere in den afrikanischen Provinzen venationes weiter verbreitet waren als munera gladiorum ${ }^{55}$.

Norische Großunternehmer veranstalteten in den dichten Wäldern Jagden, bei denen wilde Tiere, vor allem Bären, für die Spiele in den Theatern gefangen wurden ${ }^{56}$; die Versorgung der Spiele in Rom erfolgte vor allem aus den Randprovinzen ${ }^{57}$. Zahlreiche in situ angetroffene Weihegaben im Amphitheater sowie mehrere Reliefs mit Bärendarstellungen aus dem Umland der Stadt bezeugen neben Gladiatorenspielen ${ }^{58}$ die vorwiegende Ausrichtung von venationes im Virunenser Amphitheater ${ }^{59}$. Die systematische Bejagung schlug sich einerseits im Handel mit Wildtieren für Spiele in den Arenen, andererseits auch in den Ernährungsgewohnheiten der Bevölkerung nieder ${ }^{60}$. Ab dem fortgeschrittenen 2. Jahrhundert n. Chr. dürfte das Angebot an Wildkatzen (vor allem aus Nordafrika) merklich zurückgegangen sein. In den folgenden Jahrzehnten florierte der Handel mit einheimischen Arten, vor allem mit Bären, deren Handel daraufhin als einziger mit einer 2\%-igen Steuer belegt wurde ${ }^{61}$.

Reskript der Kaiser Severus und Caracalla über die Privilegien des collegium centonariorum (205 n. Chr.) in Flavia Solva identifiziert werden könnte (P. S. Leber, Die in Kärnten seit 1902 gefundenen römischen Steininschriften [1972] 54. 82 bzw. Weber 1969, 149 [Flavia Solva]; R. Lafer, Omnes collegati, »concurrite«! Brandbekämpfung im Imperium Romanum, Grazer Altertumskundliche Studien 7 [2001]).

52 P. Gros geht davon aus, dass in den Nordprovinzen Amphitheater die Funktion von Stadien und Circussen übernahmen (Gros 1996, 359).

53 Sen., De brevitatae vitae 13, 5.

${ }^{54}$ Strab. 17, 3, 4. 7; Mela 3, 104; Paus. 8, 43, 3; Plin. nat. 5, 18; 8, 15. 32. 53; Golvin 1988, 114.

55 Fulford 1989, 189 ff.; D. L. Bomgardner stellt zur Diskussion, dass ein Zusammenhang des Handels mit wilden Tieren und der römischen Agrarpolitik in den afrikanischen Provinzen bestanden hätte. In hadrianischer Zeit wurde die agrarische Nutzung der afrikanischen Provinzen intensiviert, was sich in einer großräumigen centuriatio und der Prosperität der Zentralorte und Städte niederschlug. Die Ausweitung der Agrarflächen führte unwillkürlich zu Konflikten mit der lokalen Fauna, die in ihrem natürlichen Lebensraum eingeschränkt wurde. Die Zahl der Wildtiere musste demnach nicht nur wegen der Nachfrage für die Theaterspiele in den römischen Provinzen, sondern auch wegen der expandierenden Agrarwirtschaft gering gehalten werden. Die Jagd auf Wildtiere stellte somit eine Notwendigkeit für die intensive agrarische Nutzung des Landes dar (Bomgardner 1992, 163).

${ }^{56}$ G. Winkler, Noricum und Rom, in: ANRW II 6 (1977) 218.

57 Alicu - Opreanu 2000, 24.

${ }_{58}$ Zur Tradition der Gladiatorenspiele in Virunum sei ein Graffito eines Gladiators vom Magdalensberg erwähnt (Dolenz 2004, 295 Abb. 6. 14).

59 Dolenz 2004, 303 ff. bzw. Ch. Gugl, Zwei Nemesis-Votivgaben aus dem Amphitheater von Virunum - Ikonographische Bemerkungen, in: Jernej - Gugl 2004, 323 ff. Das fast zur Gänze aus Verfüllschichten und Planierungen der Cavea stammende archäologische und zoologische Fundmaterial kann nicht zur Beurteilung der primären Prozesse oder Aktivitäten in der Arena herangezogen werden (Galik 2004, 395 ff.). Zu den venationes in Noricum sei ein Friesfragment eines Grabbaus aus dem Umland von Virunum (St. Veit a. d. Glan) mit der Darstellung eines Bären, der seine Pranken und Zähne in den Nacken eines Stieres schlägt, erwähnt (www.ubi-erat-lupa.org, ID-Nr. 4938). Für Virunum wird jedoch neben einer zivilen auch die Funktion als militärischer Exerzier- und Übungsplatz erwogen (Jernej 2004, 138).

60 A. Adam - S. Czeika, Die Tierknochen der römischen Siedlung von Gleisdorf, in: Lorenz u. a. 1995, 184 (Gleisdorf); Galik 2004, 438 ff. (Virunum); A. Galik konnte eine hohe Repräsentanz von Bärenresten mit Zerlegungsspuren nachweisen, die die Verwendung als Nutztiere in der Arena, als Speisetiere sowie als Fell- und Fettlieferanten nahe legt.

${ }^{61}$ Bomgardner 1992, 164. 
Pferdezucht entwickelte sich in Afrika nachweislich im 1. Jahrhundert n. Chr. zu einem profitablen Geschäft, die besten Rennpferde exportierte man vor allem nach Rom ${ }^{62}$. Noricum war ebenfalls berühmt für seine Pferdezucht, norische Rennpferde schätzte man bereits in der Kaiserzeit und verhandelte sie bis in die Spätantike nach Rom ${ }^{63}$. Eine Funktion der norischen Amphitheater könnte darin bestanden haben, den Pferdezüchtern eine geeignete Einrichtung zu bieten, in der sie ihre Pferde, als Vorbereitung für den Einsatz bei Circusspielen, trainieren konnten. Dies wird für die afrikanischen Provinzen angenommen, wo die große Zahl von Circussen sowohl mit der Beliebtheit der Wagen- und Pferderennen als auch der Pferdezucht erklärt wird ${ }^{64}$.

Der für Noricum gewählte, an den römischen Circus oder das Stadion erinnernde Grundrisstyp des Amphitheaters von Caesarea war besonders für Darbietungen mit hohem Bewegungsbedarf und größeren Geschwindigkeiten geeignet, wobei seine Sitzposition dem Besucher, im Gegensatz zu einem Amphitheater mit rundlicher oder deutlich elliptischer Arena, aber nur ein eingeschränktes Sichtfeld gewährte ${ }^{65}$. Die Ausgestaltung der Amphitheater von Virunum

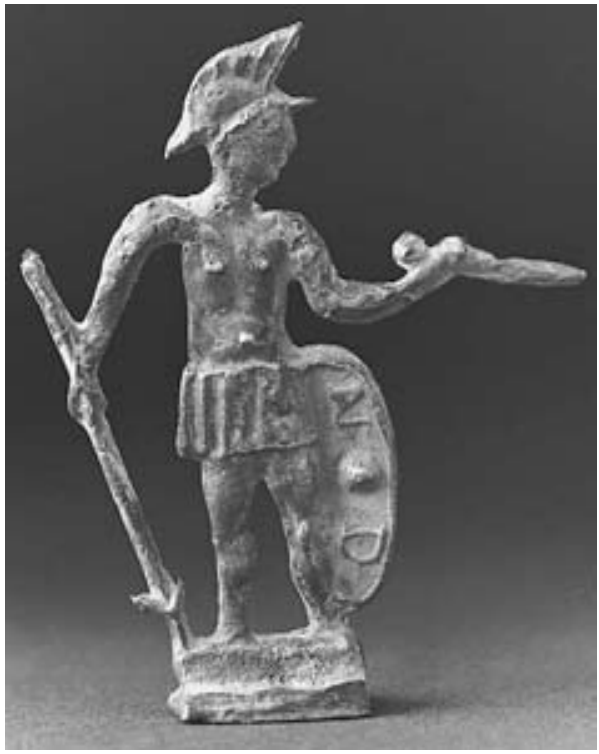

12 Votivfigur eines Gladiators aus der Insula XLI von Flavia Solva und Flavia Solva reflektierte demnach vielleicht auch einen in der Südostprovinz verbreiteten Schwerpunkt populärer Darbietungen mit venationes sowie Pferde- und Wagenrennen $^{66}$. Dies unterstreicht eine 7,5 cm hohe Votivfigur aus Flavia Solva, welche die Abhaltung von Gladiatorenspielen mit Streitwagen vermuten lässt (Abb. 12). Die Bleifigur wurde 1989 nördlich des Amphitheaters bei Grabungen in der Insula XLI gefunden und könnte in einer der zahlreichen Metall verarbeitenden Werkstätten dieses Gebäudeblocks im 2. Jahrhundert n. Chr. hergestellt worden sein ${ }^{67}$. Dargestellt ist ein mit einem Lendenschurz bekleideter Gladiator auf einem schmalen Sockel mit ovalem, gewölbtem Schild mit umbo. Auf dem Schild sind die Buchstaben N D zu lesen, die wohl mit N[emesi] D[eae] aufgelöst werden können ${ }^{68}$. In der Linken hält der Gladiator einen kurzen gladius und in der Rechten einen Wurfspeer, dessen Spitze in einem Lanzenschuh stecken dürfte. Er trägt keine Beinschienen, seinen Helm schmückt ein Kamm mit Federn.

Stangenwaffen wurden von drei Gladiatorengruppen geführt: Die ca. 2,2 m lange Stoßlanze (hasta) fand ihre Verwendung bei den hoplomachi und equites, der kürzere, ca. 1,5 m lange Wurfspeer (iaculum, telum) kam bei den essedarii zum Einsatz. Der kurze Wurfspeer, das Schwert, der rund-ovale Schild mit Schildbuckel

${ }^{62}$ M. Junkelmann, Mit Ben Hur am Start. Wagenrennen im Circus Maximus, in: E. Köhne - C. Ewigleben, Caesaren und Gladiatoren (2002) $93 \mathrm{ff}$.

${ }^{63}$ Cassiod. var. 3, 50: minoris quidem membris sed idonei ad laborem; CIL 10047. 10053. 10056. 10058 und 10082 mit der Erwähnung afrikanischer Pferde in Rom; Alföldy 1974, 108 und CIL 10056, 23: Zirkusreiter mit der Erwähnung eines Noricus r(ussus).

${ }^{64}$ J. H. Humphrey, Roman Circusses (1986) 332.

65 Vgl. dazu Golvin 1988, 307 ff. Taf. 55. 56.

${ }_{66} \mathrm{Zu}$ den ludi circensis existieren ein bemerkenswerter Fund aus der Villa rustica von Grünau im Territorium Flavia Solva, nämlich ein Silberskyphos mit der Darstellung eines Wagenrennens (E. Pochmarski, Ein Silberskyphos aus der römischen Villa von Grünau [Stmk, Österreich]. Ein Meisterwerk der römischen Toreutik, Monographies Instrumentum 21 [2002] 435 ff.) sowie ein Tonmedaillon (Brotmodel) aus Teurnia mit der Inschrift hic munus hic circus, das ein Wagenrennen im Circus Maximus zeigt (F. Glaser, Teurnia. Römerstadt und Bischofssitz [1992] 28 ff. Abb. 8).

${ }^{67}$ Das Stück mit der Inv. 23.885 (Landesmuseum Joanneum, Graz, Provinzialrömische Sammlung) wurde 1989 in sekundärer Fundlage in der Insula XLI gefunden; E. Hudeczek, Flavia Solva. Unsere erste Hauptstadt, Steirische Berichte 1, 1992, 19 [Abb.] bzw. E. Krenn, Führer durch das Museum und das Ausgrabungsgelände von Flavia Solva, MblFlavSolv, Sondernr. (1996) 23 [mit einer falschen Jahresangabe]); zur Insula XLI: Groh 1996.

${ }^{68}$ Weitere Auflösungsvorschläge sind: N(emesi) d(edit) und N(emesi) d(onum scil. dedit), N(emesi) D(ianae) oder N(emesi) D(ominae) (freundliche Mitteilung R. Wedenig, Graz; das Stück wird im Rahmen des Projektes T.E.NOR. [Testimonia Epigraphica Norica] an der Österreichischen Akademie der Wissenschaften erfasst); vgl. dazu Weber 1969, 168 (Seggauberg), ein Marmorrelief mit der Darstellung der Göttin Nemesis als Victoria und eines Gladiatorenschulenbesitzers mit der Inschrift [D]eae Nemesi (CIL 5406). 
und der Lendenschurz weisen die Votivfigur als essedarius in einer Rüstung des 2. Jahrhunderts n. Chr. aus ${ }^{69}$.

Die bevorzugte Ausrichtung von spectacula mit Streitwagenkämpfen, Tierhatzen sowie Pferde- und Wagenrennen beeinflusste die Grundrissgestaltung der Amphitheater und knüpfte womöglich an lokale keltische Traditionen in Noricum an.

\section{Zusammenfassung}

Die Errichtung von Amphitheatern in Noricum war bereits zum Zeitpunkt der Provinzeinrichtung und Gründung der Städte und Vici vorgesehen, besaß aber keine Priorität. Die Flächen für diese Großbauten wurden bei Anlage des Straßenrasters in Virunum und Flavia Solva und des Wegenetzes in Gleisdorf parzelliert und erst nach einer wahrscheinlich auch wirtschaftlichen Konsolidierungsphase oder politischen Willensbezeugung Jahrzehnte später verbaut.

Analysiert man die Verbreitungskarte der Amphitheater und Theater der römischen Provinzen ${ }^{70}$, so sind mehrere Kriterien für deren Errichtung zu erkennen: Im Mutterland Italien und in der regio $X$ waren Theaterbauten ein integraler Bestandteil des urbanistischen Gesamtkonzepts und wurden in allen größeren wirtschaftsstarken Städten errichtet. In den Nordprovinzen und in Afrika zeichnet sich jedoch ein davon abweichendes Verteilungsmuster ab, wonach in wirtschaftlich prosperierenden Provinzen, deren ökonomische Grundlage zumeist die Ausbeutung von Bodenschätzen und der Handel bildete, jede größere Stadt mit einem Theater und/oder Amphitheater bzw. einem Circus ausgestattet wurde. Besonders deutlich ist dies in der Provinz Dakien, wo im Zuge der Goldgewinnung in Porolissum, Ulpia Traiana und Micia sowie vermutlich in vier weiteren Städten Amphitheater eingerichtet wurden ${ }^{71}$, während aus den wirtschaftlich schwächeren Nachbarprovinzen keine Theaterbauten bekannt sind. Ähnlich auch die Situation in Afrika, wo sich der Großteil der über 70 Theater auf die wirtschaftlich stärksten Provinzen Numidia und Africa proconsularis konzentrieren $^{72}$. Am Rhein-Donau-Limes treten Theaterbauten nur vereinzelt und dann in den militärischen und wirtschaftlichen Zentren wie Vetera, Colonia Agrippinensis, Augusta Treverorum und Augusta Raurica auf, die Provinz Rätien besaß mit einem einfachen Holzbau im Vicus von Künzing ein einziges Amphitheater ${ }^{73}$. Auch in Pannonien errichtete man nur in den militärischen und zivilen Hauptorten am Limes in Aquincum, Brigetio und Carnuntum sowie in Scarbantia, das eine hervorragende wirtschaftliche Stellung an der Bernsteinstraße einnahm, Amphitheater.

Im norischen Limesabschnitt gab es kein Amphitheater, die Bauten in Gleisdorf, Flavia Solva und Virunum reflektieren mit ihrer topographischen Nähe zueinander die wirtschaftliche Potenz des südöstlichen Provinzgebiets $^{74}$. Der Hauptgrund für die Einrichtung von drei Amphitheatern im Süden von Noricum dürfte demnach

\footnotetext{
${ }^{69}$ Der Name dieser Gladiatoren wird von essedem, der römischen Bezeichnung für einen zweirädrigen keltischen Streitwagen, abgeleitet. Da auch die Ausrüstung der essedarii oft keltische Anklänge zeigte, handelte es sich bei diesen Gladiatoren möglicherweise anfänglich um keltische Kriegsgefangene. Streitwagenkämpfer fochten, nach Ausweis der Inschriften, immer untereinander; sie eröffneten den Kampf auf dem Streitwagen, schleuderten ihre Wurfspeere, um danach die Entscheidung im Duell mit dem Schwert zu suchen. Die detailgetreue Darstellung der einzelnen Gladiatorengattungen ist durch zahlreiche Bronzestatuetten belegt (M. Junkelmann, Das Spiel mit dem Tod. So kämpften Roms Gladiatoren [2000] 94 und 116 ff. Abb. 15. 118. 156. 157. 181.184. 190).

${ }^{70}$ Golvin 1988, Taf. 71.

${ }^{71}$ Alicu - Opreanu 2000, 28 ff. Abb. 4.

72 Bomgardner 1992, 163.

${ }^{73}$ Der Holzbau mit einer rundovalen $35 \times 31 \mathrm{~m}$ bzw. ca. $850 \mathrm{~m}^{2}$ großen, eingetieften Arena dürfte im 2. Jh. n. Chr. errichtet worden sein: K. Schmotz, Das römische Amphitheater von Künzing, Lkr. Deggendorf (http://www.gesellschaft-fuer-archaeologie.de/mat/ kuenzing.pdf) und ders., Ein Vierteljahrhundert Kommunalarchäologie im Landkreis Deggendorf, Das archäologische Jahr in Bayern (2003) 162 Abb. Umschlag. Der Bau lässt sich gut mit dem zeitgleichen, 31,6 × 29,5 m großen Amphitheater von Micia (Dakien) vergleichen, dessen Arena jedoch von einer Steinmauer eingefasst war. Diese kleinen, einfachen Amphitheater dürften im Umfeld von Militäranlagen gebaut worden sein (Alicu - Opreanu 2000, 42 ff. und Golvin 1988, 90 Taf. 12, 4).

${ }^{74}$ „Ein Amphitheater für Gladiatorenspiele und Tierjagden besaßen außerhalb Italiens in der Regel nur Provinzhauptstädte.« (F. Kolb, Die Stadt im Altertum [1984] 193).
} 
in der durch die Gold- und Eisenerzgewinnung sowie Buntmetall- und Eisenverarbeitung begründeten wirtschaftlichen Prosperität zu suchen sein ${ }^{75}$.

Die Errichtung der Amphitheater, die Wahl des Bautyps und die Verbreitung im Provinzgebiet hatten demnach primär ökonomische und städteplanerische Gründe, sekundär waren jedoch auch individuelle Entscheidungen der zentralen und lokalen Nobilität von Einfluss.

Es ergibt sich das Bild einer wirtschaftsstarken Südostregion der Provinz, deren Basis vor allem die Gold-, Buntmetall- und Eisenverarbeitung bildete. Die Nutznießer dieser Wirtschaftsentwicklung strebten überregionale politische Karrieren im Römischen Reich an. Individuelle Karrieren und Erfahrungen spielten eine entscheidende Rolle, wenn es darum ging, urbanistische Gestaltungskonzepte umzusetzen und Bautypen nach Noricum zu transferieren, wobei wiederum familiäre Beziehungen innerhalb der Provinz für die Verbreitung der Bautypen ausschlaggebend gewesen sein könnten. Die Errichtung und architektonische Ausgestaltung des Repräsentationsbaus Amphitheater orientierte sich in Noricum an den lokalen Bedürfnissen und Traditionen, welche wiederum eng mit den ökonomischen Grundlagen verknüpft waren.

\section{Abgekürzt zitierte Literatur}

Alföldy 1974

Alicu - Opreanu 2000

Bomgardner 1992

Dolenz 2004

Fulford 1989

Galik 2004

Gömöri 1994

Golvin 1988

Golvin - Leveau 1979

Groh 1996

Gros 1996

Hudeczek 1979

Jernej 2004

Jernej - Gugl 2004

Lorenz u. a. 1995

Maier 1995

Piccottini 1989

Weber 1969

Schmid 1919

Winkler 1969
G. Alföldy, Noricum (1974).

D. Alicu - C. Opreanu, Les amphithéâtres de la Dacie romaine (2000).

D. L. Bomgardner, The Trade in Wild Beasts for Roman Spectacles: A Green Perspective, Anthropozoologica 16, 1992, 161-166.

H. Dolenz, Die Inschriften aus dem Amphitheater von Virunum, in: Jernej - Gugl 2004, 269-322.

M. Fulford, The Silchester Amphitheatre, Britannia Monographs Series 10 (1989).

A. Galik, Archäozoologische und kulturhistorische Aspekte der Tierknochenvergesellschaftungen aus dem Amphitheater von Virunum, in: Jernej - Gugl 2004, 395-494.

J. Gömöri, Recent Archaeological Finds Concerning the Topography of Scarbantia, in: G. Hajnóczi (Hrsg.), La Pannonia e l’impero romano, Annuario dell'accademia d’Ungheria (1994) 251-261.

J.-C. Golvin, L’amphithéâtre romain (1988).

J.-C. Golvin - Ph. Leveau, L’amphithéâtre et le théâtre-amphithéâtre de Cherchel: Monuments à spectacle et histoire urbaine à Caesarea de Maurétanie, MEFRA 91, 1979, 818-843.

St. Groh, Die Insula XLI von Flavia Solva, SoSchrÖAI 28 (1996).

P. Gros, L'architecture romaine I (1996).

E. Hudeczek, Flavia Solva, in: ANRW II 6 (1977) 414-471.

R. Jernej, Zur Erforschung von Virunum und seines Amphitheaters, in: Jernej - Gugl 2004, 13-21.

R. Jernej - Ch. Gugl (Hrsg.), Virunum. Das römische Amphitheater, Archäologie Alpen Adria 4 (2004).

Th. Lorenz u. a. (Hrsg.), Der römische Vicus von Gleisdorf, VIKAGraz 2 (1995).

Ch. Maier, Der vicus von Gleisdorf, in: Lorenz u. a. 1995, 21-60.

G. Piccottini, Die Römer in Kärnten (1989).

E. Weber, Die römerzeitlichen Inschriften der Steiermark. Veröffentlichungen der Historischen Landeskommission für Steiermark, Arbeiten zur Quellenkunde XXXV (1969).

W. Schmid, Flavia Solva bei Leibnitz in Steiermark, ÖJh 19/20, 1919, Beibl. 135-156.

G. Winkler, Die Reichsbeamten von Noricum und ihr Personal bis zum Ende der römischen Herrschaft, SBWien 261 (1969).

Doz. Dr. Stefan Groh

Österreichisches Archäologisches Institut, Franz Klein-Gasse 1, A-1190 Wien

E-Mail: stefan.groh@oeai.at

${ }^{75}$ Ch. Gugl, Überlegungen zur Struktur, Funktion und Entwicklung der Siedlung, in: A. Galik - Ch. Gugl - G. Sperl, Feldkirchen in Kärnten. Ein Zentrum norischer Eisenverhüttung, AForsch 9 (2003) 54 ff.; G. Piccottini, Norisches Gold für Rom, AnzWien 136, 2001, 41 ff.; E. Hudeczek, Zu den Kleinbronzegießereien in Flavia Solva (Steiermark), in: K. Gschwantler - A. BernhardWalcher, Griechische und römische Statuetten und Großbronzen (1986) 341 ff.; W. Artner - B. Hebert - D. Kramer, Die vorläufigen Ausgrabungsergebnisse auf der Parzelle 1166/1 in Kalsdorf, AÖ 2/2, 1991, 43; Maier 1995, 35 ff. bzw. H. Preßlinger, Metallurgische Untersuchungsergebnisse der Schlacken und Metallproben, in: Lorenz u. a. 1995, 177 ff. 
Abbildungsnachweis: Abb. 1: Kartengrundlage Shuttle Radar Topographic Mission (SRTM) 3, Kartengestaltung V. Lindinger, ÖAI 2005; Abb. 2: Lorenz u. a. 1995, Taf. 8 Abb. 16; Abb. 3: Hudeczek 1979, 456 Abb. 14; Abb. 4: Groh 1996, Plan 17; Abb. 5: Photo ÖAI 2004; Abb. 6: Jernej 2004, 27 Abb. 2, 3; Abb. 7: Gugl 2004, 14 Abb. 1.1; Abb. 8: Vorlagen: 1: Lorenz u. a. 1995, Taf. 8 Abb. 16; 2-3: Hudeczek 1979, 456 Abb. 14; 4: Jernej 2004, 27 Abb. 2, 3; 5: Golvin - Leveau 1979, 820 Abb. 2; Digitalisierung I. Benda-Weber, ÖAI 2004; Abb. 9: Golvin - Leveau 1979,821 Abb. 3; Abb. 10: Vorlagen: Piccottini 1989, 176 Abb. 122 bzw. Golvin - Leveau 1979, 820 Abb. 2; Abb. 11: Gömöri 1994, 257 Abb. 3; Abb. 12: Hudezek 1992, 19. 